\title{
Tracking the relationship between euro area equities and sovereign bonds
}

\section{Inês da Cunha Cabral*}

ISEG, Lisbon School of Economics and Management, Universidade de Lisboa, Banco de Portugal, Rua do Quelhas 6, 1200-781 Lisboa, Portugal Email: cunha.c.ines@gmail.com

${ }^{*}$ Corresponding author

\section{Pedro Pires Ribeiro}

Banco de Portugal; Instituto Universitário de Lisboa (ISCTE-IUL), Business Research Unit (BRU-IUL), Av. Almirante Reis, 71, 1150-012, Lisboa, Portugal

Email: ppribeiro@bportugal.pt

\section{João Nicolau}

ISEG, Lisbon School of Economics and Management, Universidade de Lisboa, REM/CEMAPRE, Rua do Quelhas 6, 1200-781 Lisboa, Portugal Email: nicolau@iseg.ulisboa.pt

\begin{abstract}
This paper explores the relationship between stocks and sovereign bonds by means of the asymmetric detrended cross-correlation analysis (ADCCA). Drawing on data from 1999.01 to 2018.09 of the first wave of euro area countries, the full sample is divided into three subsets in accordance with economic and financial features. Some findings arise with striking implications for investors and policymakers. Firstly, empirical results show that cross-correlations differ from country to country, depending on the sub-period under analysis and on the time scale. Secondly, likewise within country estimates, cross-country linkages may point to fragmentation in the euro area with agents moving away from financial assets of lower-rated countries to invest in more robust economies in periods of turmoil. Thirdly, there is evidence of asymmetry since 'flight-to-quality' movements seem to be more relevant than 'flight-to-yield' episodes. Finally, while relationships were globally bidirectional until mid-2007, new causality patterns arose with the financial crisis.
\end{abstract}

Keywords: equities; sovereign bonds; euro area; fragmentation; crosscorrelation; multiscales; asymmetry; causality.

Reference to this paper should be made as follows: Cabral, I.C., Ribeiro, P.P. and Nicolau, J. (2019) 'Tracking the relationship between euro area equities and sovereign bonds', Int. J. Monetary Economics and Finance, Vol. 12, No. 6, pp.511-537. 
Biographical notes: Inês da Cunha Cabral is a $\mathrm{PhD}$ candidate in Applied Mathematics for Economics and Management at ISEG - Lisbon School of Economics and Management. Currently, she works at Banco de Portugal in the Monetary Policy Implementation Division. Before joining the Markets and Reserve Management Department, in 2016, she worked in the Risk Management Department at the same institution and in the Financial Management Division of Banco Santander Totta. Additionally, she served as teaching assistant at ISCTE-IUL. Her research interests are focused on financial markets, risk management and econometrics.

Pedro Pires Ribeiro is Economist at Banco de Portugal and Invited Professor of Finance. He holds a PhD in Finance from ISCTE-IUL and his interests are mainly focused on the areas of financial markets, portfolio management, risk management and monetary policy. He has published articles in journals such as the Review of World Economics, Empirical Economics and Finance Research Letters.

João Nicolau is a Full Professor of Econometrics at ISEG/University of Lisbon. He has published articles in journals such as the Review of Economics and Statistics, Econometric Theory, Scandinavian Journal of Statistics, Econometric Journal, Journal of Financial Econometrics, among many others. He received the Econometric Theory Multa Scripsit Award "In Recognition of Research Contributions". He is currently member of the Scientific Council of ISEG/University of Lisbon, coordinator of the scientific area of Econometrics at the ISEG/University of Lisbon and Director of the Master Course in Applied Econometrics and Forecasting at the same faculty.

\section{Introduction}

Stocks and government bonds account for a dominant share in all traded financial markets and understanding the interconnectedness across these financial asset classes is a cornerstone of asset allocation strategies, risk management and monetary policy decisions.

Given its relevance, the linkage between stocks and bonds has received particular attention in the literature, with several authors stating that these assets can exhibit both positive and negative correlations, depending on the time period and the relative importance of the factors that affect this relationship (see, e.g., Gulko, 2002; Ilmanen, 2003).

The ties between equity and debt instruments may be affected by a host of determinants whose influence is not straightforward and which have been changing over time. Firstly, both actual inflation and inflation expectations are likely to play an important role in explaining the dynamics of the stock-bond correlation given that a positive figure is found when inflation rates and inflation expectations are high, ${ }^{1}$ while opposite co-movements stand out in periods of deflation and low inflation outlook (see, e.g., Ilmanen, 2003; Andersson et al., 2008). Secondly, business cycles and volatility conditions are prone to have an effect on the behaviour of stocks and bonds, once these instruments tend to exhibit opposite sensitivities to growth and volatility, i.e., in periods of economic expansion, stocks usually perform better than bonds, while bonds outperform stocks during economic recessions. Indeed, in periods of financial turbulence, 
agents have less appetite to take risks, meaning that investors shift funds from the stock markets to the safe-haven instruments, namely high-quality bonds, causing the so-called 'flight-to-quality' phenomenon (see, e.g., Gulko, 2002; Ilmanen, 2003; Connolly et al., 2005; Andersson et al., 2008). On the other hand, at times of stock market mounts, the literature supports 'flight-from-quality' movements (see, e.g. Baur and Lucey, 2008). Thirdly, monetary policy may also weigh on the pattern of positive cross-correlations in the sense that an accommodative (contractionary) stance boosts (hampers) the performance of both instruments (see, e.g., Ilmanen, 2003). Yang et al. (2009) and Skintzi (2019) comprehensively report the prominent role of the inflation environment, business cycle and monetary policy stance in modelling these linkages.

Another strand of literature illustrates the time-varying nature of the link between stocks and bonds (see, e.g., de Goeij and Marquering, 2004; Wu and Lin, 2014; Nguyen and Nguyen, 2014). Cappiello et al. (2006) add their contribution to this field of research by introducing asymmetries in the stock-bond correlation considering a sample of European, Australian and North-America countries. Besides analysing how these linkages have been evolving over various time spans, many empirical studies on stock-bond correlations draw comparisons across jurisdictions. Among other authors, Hartmann et al. (2004) characterise these linkages during periods of stress in Germany (DE), France (FR), Japan (JP), the United Kingdom (UK) and the United States (USA) while Kim and In (2007) centre their work on the Group of Seven (G7).

In the specific context of the Economic and Monetary Union (EMU), the literature has mainly focused on the stock and bond markets separately (see, e.g. Cipollini et al., 2015; Fonseca, 2016; Lukić, 2016). However, these instruments deserve further investigation, namely regarding their interconnectedness. While it is undeniable that the introduction of the single currency increased financial integration in the euro area which enhanced its resilience as a whole, Members States still have their own idiosyncrasies and the institutional architecture of the Monetary Union did not prevent the European financial markets from being affected in different ways by economic and financial shocks.

Therefore, this paper aims to provide thorough information on how main euro area stocks and bonds have evolved since the introduction of the euro. Overall, this investigation complements the research on this topic (see, e.g., Jammazi et al., 2015; Perego and Vermeulen, 2016) by analysing the co-movements between the two asset classes within each country and across jurisdictions over different time scales. The existing studies are not so extensive because they either group euro area countries according to their geographic location, thus ignoring countries' specificities, or they do not cover cross-correlations between financial securities from different jurisdictions. In addition, they disregard the distinct investment time horizons that agents may have. In this analysis special attention is also given to eventual asymmetric features and causal relationships, which have not yet been deeply explored in the context of the single currency.

More specifically, this study relies on benchmark equity indices and sovereign bonds from the first wave of euro area Member States joining the EMU. The analysis takes into account diverse time scales by considering a time span that runs from 1999.01 to 2018.09. This sample is then split into three sub-periods: from 1999.01 to 2007.06; from 2007.07 to 2012.06, covering the period of greater turbulence in the wake of the global financial crisis and the European sovereign debt crisis; and from 2012.07 to 2018.09, encompassing the period after the peaks of economic and financial turmoil. 
To track the relationship between the euro area stocks and sovereign bonds, the detrended cross-correlation analysis (DCCA) originally developed by Podobnik and Stanley (2008) is implemented. This method, which consists of a generalisation of the detrended fluctuation analysis (DFA) proposed by Peng et al. (1994) to detect temporal dependence in time series, has the advantage of being applied in the context of nonstationarity (see, e.g., Zebende et al., 2013; Kristoufek, 2014), thereby circumventing econometric problems related to unit roots and periodic trends that may lead to spurious results. As documented by Bashir et al. (2016), the DCCA correlation coefficient proposed by Zebende (2011) proved to be more robust than the linear models in the presence of such issues. Accordingly, by means of this methodology it is possible to grasp if there are co-movements between equity and debt instruments at different scales, which may be relevant to support investors' decisions. It is important to mention that, following the co-integration and vector autoregressive (VAR) approaches, most of the studies consider only one or two time scales, therefore not much is known about the dynamics of these two markets at varying time scales. This approach is employed not only to securities of each country, but also to figure out the correlations between stocks and bonds of different jurisdictions. This additional assessment may be useful to find out how concerns about the dynamics of financial instruments associated with a specific Member State may affect the performance of financial assets of other EMU jurisdictions.

The analysis proceeds with the asymmetric extension of the DCCA (ADCCA) and the associated cross-correlation coefficient as proposed by Wang (2016) to distinguish time series upward trends from downwards trends. In the spirit of Baur and Lucey (2008) and Dean et al. (2010), the application of the ADCCA shows to what extent cross-correlations evolve when stock or bond markets rise or fall.

Finally, given that correlation does not necessarily imply causality, the Granger causality test of Toda and Yamamoto (1995) is employed to test an eventual causal relationship between sovereign bonds and stocks. Although not distinguishing between short-run and long-run causality, this procedure has recognised merits in overcoming issues related to the power and size properties of traditional unit root and to cointegration tests, as it specifies a VAR model in levels (see, e.g., Jain and Ghosh, 2013 or Iheanacho, 2017). This technique is therefore suitable to deal with time series that have different orders of integration, are not co-integrated or both.

This paper contains at least three main contributions. Firstly, the research sheds new light on how main euro area stocks and bonds evolved under distinct economic and financial conditions. To this end, it analyses cross-correlations both within each country and across countries, while also probing asymmetric features and causal relationships. In this vein, the present study devotes particular attention to the signals of fragmentation in the EMU financial markets, which is a topic that has been attracting special interest since the beginning of the European sovereign debt crisis (see, e.g., Gödl and Kleinert, 2016; Ehrmann and Fratzscher, 2017; Ribeiro et al., 2017). Secondly, given that agents have different investment horizons, the assessment of equity and debt instrument co-movements is originally made for different time scales. Thirdly, to the best of our knowledge, using the DCCA and its asymmetric version to explore euro area financial integration within the scope of this investigation is a novelty.

All in all, this study has significant implications for several agents. On the one hand, there are key conclusions for asset allocation and risk management. As a matter of fact, the correlation between stocks and government securities is a relevant variable in investors' decisions since it helps to determine the overall risk of their portfolios. 
Accordingly, a weak or a negative correlation improves hedging strategies and offers benefits in terms of financial risk diversification. On the other hand, there are important conclusions for policymakers, calling for the adoption of measures to calm down financial market tensions and to abate fragmentation concerns.

The remainder of this paper is organised as follows. Section 2 introduces the methodology. Section 3 describes the data. Section 4 presents the results and discusses their main implications. Lastly, a brief conclusion is given in Section 5.

\section{Econometric methodology}

\subsection{Correlation}

This section outlines the econometric strategy that will be followed to assess the cross-correlation between the performance of benchmark stock indices and sovereign bonds.

Under the context of two non-stationary time series, the ADCCA is prone to offer the best solution to explore the linkage between equity and debt instruments as it modifies the standard covariance, replacing the global mean by local trends (see, e.g., Podobnik et al., 2011). Briefly, based on this methodology, it is possible to conduct a comprehensive analysis: ascertaining if there are cross-correlations by means of the traditional DCCA; characterising the cross-correlation in terms of upward and downward trends through the asymmetric feature; and quantifying the relationship between the variables under inspection along the lines of the cross-correlation coefficient proposed by Zebende (2011) and the corresponding significance tests developed by Podobnik et al. (2011).

Below is a description of the methodology used.

Phase 1: Considering two time series $\left\{x_{t}^{(1)}\right\}$ and $\left\{x_{t}^{(2)}\right\}$ with the same length, $N$, the following profile is constructed:

$$
y^{(i)}(j)=\sum_{t=1}^{j}\left(x_{t}^{(i)}-\bar{x}^{(i)}\right), \quad j=1,2, \ldots, N, i=1,2
$$

where $\bar{x}^{(i)}$ corresponds to the mean of the time series $\left\{x_{t}^{(i)}\right\}$.

Phase 2: The time series $\left\{x_{t}^{(i)}\right\}$ and the corresponding profiles $\left\{y_{t}^{(i)}\right\} \quad(i=1,2)$ are then divided into $N_{n}=\operatorname{int}(N / n)$ non-overlapping segments of length $n$. However, as the length $N$ of the series is not always a multiple of the time scale $n$, it is possible that a short part at the end of each profile is not included. As such, the same procedure is repeated starting from the opposite, which means that $2 N_{n}$ segments are obtained altogether. The time scale is set $10<n<N / 5$ as Wang et al. (2011) suggest.

Also, it is assumed that $S_{j}^{(i)}=\left\{s_{j, k}^{(i)}, k=1, \ldots, n\right\}$ is the $j$ th sub-time series with length $n$ and $Y_{j}^{(i)}=\left\{y_{j, k}^{(i)}, k=1, \ldots, n\right\}$ is the according profile $j$ th time interval, $j=1,2, \ldots, 2 N_{n}$. In the $j$ th segment, $s_{j, k}^{(i)}=x_{(j-1) n+k}^{(i)}, y_{j, k}^{(i)}=y_{(j-1) n+k}^{(i)}$ for $j=1, \ldots, N_{n}$ and $s_{j, k}^{(i)}=x_{N-\left(j-N_{n}\right) n+k}^{(i)}$, $y_{j, k}^{(i)}=y_{N-\left(j-N_{n}\right) n+k}^{(i)}$, for $j=N_{n}+1, \ldots, 2 N_{n}$, where $k=1,2, \ldots, n$. 
Phase 3: For each sub-time series, $S_{j}^{(i)}$, and its profile time series, $Y_{j}^{(i)}$, the local linear trends can be figured out as $L_{S_{j}^{(i)}}(k)=a_{S_{j}^{(i)}}+b_{S_{j}^{(i)}} k$ and $L_{Y_{j}^{(i)}}(k)=a_{Y_{j}^{(i)}}+b_{Y_{j}^{(i)}} k$, respectively, where $k$ is the horizontal coordinate and $i=1,2$.

The slope $b_{S^{(i)}}$ is used to discriminate if the trend of the sub-time series $S_{j}^{(i)}$ is positive or negative. The linear fit $L_{Y_{i}^{(i)}}(k)$ is then applied to detrend the integrated time series $Y_{j}^{(i)}$.

The detrended covariance of the residuals is determined for each segment $j$, where $j=1,2, \ldots, 2 N_{n}$ :

$$
f_{D C C A}(n, j)=\frac{1}{n} \sum_{k=1}^{n}\left(y_{j, k}^{(1)}-L_{Y_{j}^{(1)}}(k)\right) \cdot\left(y_{j, k}^{(2)}-L_{Y_{j}^{(2)}}(k)\right)
$$

Phase 4: The average 2nd order fluctuation function is given by:

$$
F_{D C C A}^{2}(n)=\frac{1}{2 N_{n}} \sum_{j=1}^{2 N_{n}} f_{D C C A}(n, j)
$$

In a similar way, the detrended covariance functions are considered to assess the asymmetric cross-correlation scaling properties when the time series $x^{(i)}$ has piecewise positive or negative linear trends. This differentiation is made by using the sign of the slope $b_{S^{(i)}}$, i.e., $b_{S^{(i)}}>0$ (resp., $b_{S_{i}^{(i)}}<0$ ) indicates time series $x^{(i)}$ with positive (resp., negative) trend in the sub-time series $S_{j}^{(i)}$.

Therefore, it is possible to assess the asymmetric cross-correlation between two instruments caused by different trends of one time series. In this case, the directional 2nd order average fluctuation functions, $f_{D C C A}$, over all segments are given by:

$$
\begin{aligned}
& F_{D C C A}^{2+}(n)=\frac{1}{M_{i}^{+}} \times \sum_{j=1}^{2 N_{n}} \frac{\operatorname{sign}\left(b_{s_{j}^{(i)}}\right)+1}{2} \times f_{D C C A}(n, j) \\
& F_{D C C A}^{2-}(n)=\frac{1}{M_{i}^{-}} \times \sum_{j=1}^{2 N_{n}} \frac{-\left[\operatorname{sign}\left(b_{s_{j}^{(i)}}\right)-1\right]}{2} \times f_{D C C A}(n, j)
\end{aligned}
$$

where

$$
M_{i}^{+}=\sum_{j=1}^{2 N_{n}} \frac{\operatorname{sign}\left(b_{s_{j}^{(i)}}\right)+1}{2} \text { and } M_{i}^{-}=\sum_{j=1}^{2 N_{n}} \frac{-\left[\operatorname{sign}\left(b_{s_{j}^{(i)}}\right)-1\right]}{2}
$$

are the numbers of sub-time series $\left\{x_{t}^{(i)}\right\}(i=1,2)$ with positive and negative trends, respectively.

In the presence of cross-correlations, there are power-law relationships between the average fluctuation functions and the scale, $n$ :

$$
F_{D C C A}^{2}(n) \sim n^{2 \lambda} \quad F_{A D C C A}^{2+}(n) \sim n^{2 \lambda+} \quad F_{A D C C A}^{2-}(n) \sim n^{2 \lambda-}
$$

where $\lambda, \lambda^{+}$and $\lambda^{-}$are the so called long-range power-law cross-correlation exponents that can be obtained by observing the slope of the $\log -\log F_{D C C A}$ vs. $n$ graph, considering ordinary least squares (OLS). 
Phase 5: To quantify the cross-correlation between series the DCCA/ADCCA coefficient is estimated. To do so, it is important to recall that when $x_{t}^{(1)}=x_{t}^{(2)}$, the detrended covariance $f_{D C C A}(n, j)$ is replaced by the detrended variance, $f_{i}(n, j)$ :

$$
f_{i}(n, j)=\frac{1}{n} \sum_{k=1}^{n}\left(y_{j, k}^{(i)}-L_{Y_{j}^{(i)}}(k)\right)^{2}, \text { for } i=1,2
$$

and the 2 nd order average fluctuation function of series $x^{(i)}$ is extracted by:

$$
F_{D F A_{i}}(n)=\left(\frac{1}{2 N_{n}} \sum_{j=1}^{2 N_{n}} f_{i}(n, j)\right)^{1 / 2}, \text { for } i=1,2
$$

After obtaining the 2nd order fluctuation functions, the detrended cross-correlation coefficient, $\rho_{D C C A}$, can be computed as:

$$
\rho_{D C C A}(n)=\frac{F_{D C C A}^{2}(n)}{F_{D F A_{1}}(n) \times F_{D F A_{2}}(n)}
$$

This coefficient can also be extended to determine the two directional coefficients denoted by $\rho_{A D C C A}^{+}(n)$ and $\rho_{A D C C A}^{-}(n)$. The DCCA coefficient to quantify asymmetric cross-correlation between series can be estimated as:

$$
\rho_{A D C C A}^{+}(n)=\frac{F_{A D C C A}^{2+}(n)}{F_{D F A_{1}}^{+}(n) \times F_{D F A_{2}}^{+}(n)} \quad \rho_{A D C C A}^{-}(n)=\frac{F_{A D C C A}^{2-}(n)}{F_{D F A_{1}}^{-}(n) \times F_{D F A_{2}}^{-}(n)}
$$

where

$$
\begin{aligned}
& F_{D F A_{i}}^{+}(n)=\left(\frac{1}{M_{i}^{+}} \times \sum_{j=1}^{2 N_{n}} \frac{\operatorname{sign}\left(b_{s_{j}^{(i)}}\right)+1}{2} \times f_{i}(n, j)\right)^{1 / 2}, \text { for } i=1,2 \\
& F_{D F A_{i}}^{-}(n)=\left(\frac{1}{M_{i}^{-}} \times \sum_{j=1}^{2 N_{n}} \frac{-\left[\operatorname{sign}\left(b_{s_{j}^{(i)}}\right)-1\right]}{2} \times f_{i}(n, j)\right)^{1 / 2}, \text { for } i=1,2
\end{aligned}
$$

\subsection{Causality}

Toda and Yamamoto (1995) propose a handy procedure that fits a VAR model to the levels of the variables, which minimises the risks resulting from a possible incorrect identification of the order of integration of the series. Specifically, according to this approach, the correct VAR order, $k$, is artificially augmented by the maximum order of integration, $d_{\max }$. The VAR model in levels at the $\left(k+d_{\max }\right)$ th order is then estimated with the coefficients of the last lagged $d_{\max }$ vector ignored. This modified Wald test ensures that the usual test statistics for the Granger non causality have the standard asymptotic distribution as mentioned by Wolde-Rufael (2006). In this paper, the VAR system has the following specification:

$$
x_{t}^{(1)}=\alpha_{0}+\sum_{i=1}^{k}\left(\alpha_{1 i} \times x_{t-i}^{(1)}\right)+\sum_{j=k+1}^{k+d_{\max }}\left(\alpha_{2 j} \times x_{t-j}^{(1)}\right)+\sum_{i=1}^{k}\left(\delta_{1 i} \times x_{t-i}^{(2)}\right)+\sum_{j=k+1}^{k+d_{\max }}\left(\delta_{2 j} \times x_{t-j}^{(2)}\right)+\lambda_{1}
$$




$$
x_{t}^{(2)}=\beta_{0}+\sum_{i=1}^{k}\left(\beta_{1 i} \times x_{t-i}^{(2)}\right)+\sum_{j=k+1}^{k+d_{\max }}\left(\beta_{2 j} \times x_{t-j}^{(2)}\right)+\sum_{i=1}^{k}\left(\varphi_{1 i} \times x_{t-i}^{(1)}\right)+\sum_{j=k+1}^{k+d_{\max }}\left(\varphi_{2 j} \times x_{t-j}^{(1)}\right)+\lambda_{2 t}
$$

The null hypothesis of non-causality is rejected if $p$-values fall within the conventional significance levels. Hence, in equation (13), Granger causality from $x_{t}^{(2)}$ to $x_{t}^{(1)}$ implies that $\delta_{1 i} \neq 0, \forall i$. Similarly, in equation (14), $x_{t}^{(1)}$ Granger causes $x_{t}^{(2)}$ if $\varphi_{1 i} \neq 0, \forall i$.

\section{Sample}

As previously mentioned, this study assesses the cross-correlation between the euro area equity indices and 2-year sovereign bonds for the large majority of the first set of countries that adopted the single currency in 1999: Austria (AT), Belgium (BE), Finland (FI), DE, FR, Ireland (IE), Italy (IT), Netherlands (NL), Portugal (PT) and Spain (ES). ${ }^{2}$ The period underpinning the empirical analysis runs from 1999.01 to 2018.09, considering daily data. In order to isolate the impact that the global financial crisis and the European sovereign debt crisis might have had on these co-movements, the sample is divided into three subsets: the pre-crises period spans from 1999.01 to 2007.06; the phase of financial turmoil runs from 2007.07 to 2012.06 ; and the period from 2012.07 to 2018.09. ${ }^{3}$

The dataset is sourced from Bloomberg.

Figure 1 depicts the evolution of the euro area stocks and sovereign bonds from 1999.01 to 2018.09 for DE, FR, ES and IT. Based on these graphs, the two variables tended to follow opposite and remarkably synchronised movements before and during the crises. However, this negative pattern is not so clear in the third sub-period, turning even positive at times. For the sake of parsimony, the remaining countries under investigation are not graphically displayed. Nevertheless, this evolution is globally observed throughout the sample.

\section{Empirical results}

\subsection{Preliminary analysis}

Following the standard econometric practice in the study of financial time series, the empirical analysis starts with the data unit roots tests, which are carried out through the ADF (Dickey and Fuller, 1981) test ${ }^{4}$ and the PP (Phillips and Perron, 1988) test. According to the results, ${ }^{5}$ these tests fail to reject the null hypothesis of non-stationarity for the majority of jurisdictions and subsets considered. These findings support the application of the ADCCA to assess the power-law cross-correlations between these two time series. ${ }^{6}$

\subsection{DCCA: long-range cross-correlation}

The DCCA method is designed to investigate time series dynamics by means of the detrended covariance function $F_{D C C A}^{2}(n)$. Recalling, if long-range cross-correlation appears between two variables, then $F_{D C C A}^{2}(n) \sim n^{2 \lambda}$. 
Figure 1 Evolution of equity and sovereign bonds over 1999-2018
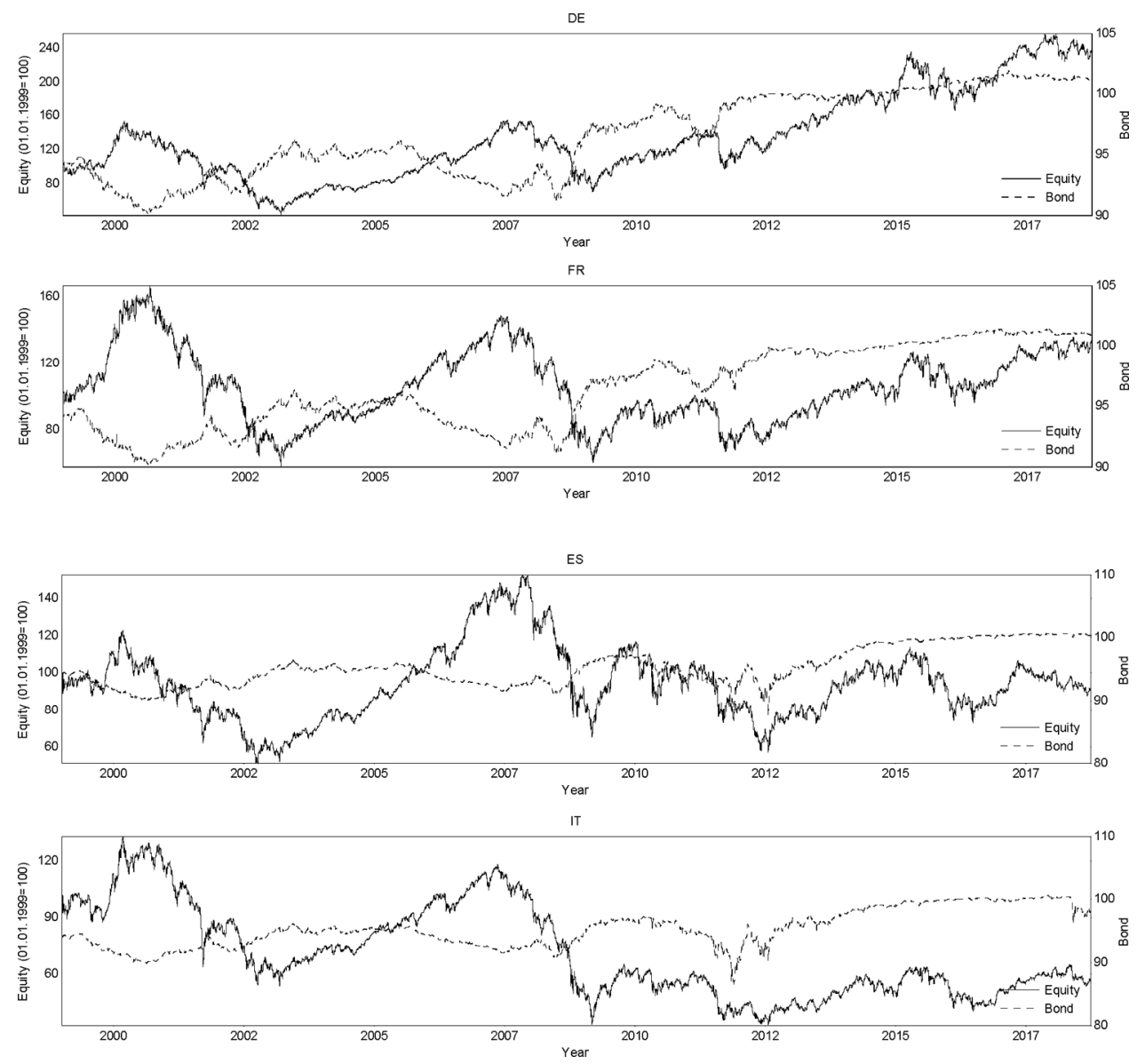

Figures 2-4 display the average fluctuation function, $F_{D C C A}^{2}(n)$, in relation to $n$, in a log$\log$ scale, for the various jurisdictions along the three subsets under inspection. In order to quantify the level of co-movements, the DCCA coefficient, $\rho_{D C C A}$, is also computed for different time scales and for the various subgroups. The results are reported in the aforementioned figures as well as the upper and lower limits estimated with $95 \%$ confidence interval (CI) conforming to Podobnik et al. (2011). Note that if the estimated coefficients, $\rho_{D C C A}$, fall out of the CI, i.e., $\left|\rho_{D C C A}\right|>\left|\rho_{c}\right|$, cross-correlations are considered statistically significant, otherwise the null hypothesis that the two series are not cross-correlated is not rejected.

At a broad level, the linear representations exhibited in Panel A of Figure 2 suggests that power-law cross-correlations exist between benchmark equity indices and sovereign bonds over the period before the onset of the global financial crisis, in 2007. Complementing this analysis, Panel B of this figure unveils evidence of a general negative and statistically significant linkage between these two markets over this time span. Overall, this effect becomes stronger as the time scale increases, thus indicating that these two assets were more closely linked throughout the long run. To better grasp the magnitude of these correlations, Table 1 displays the average values of the estimated DCCA coefficients for different intervals of time scales. 
520

I.C. Cabral et al.

Figure 2 DCCA between equity and sovereign bonds from 1999.01 to 2007.06

Panel A: 2nd order average fluctuation function (absolute value)
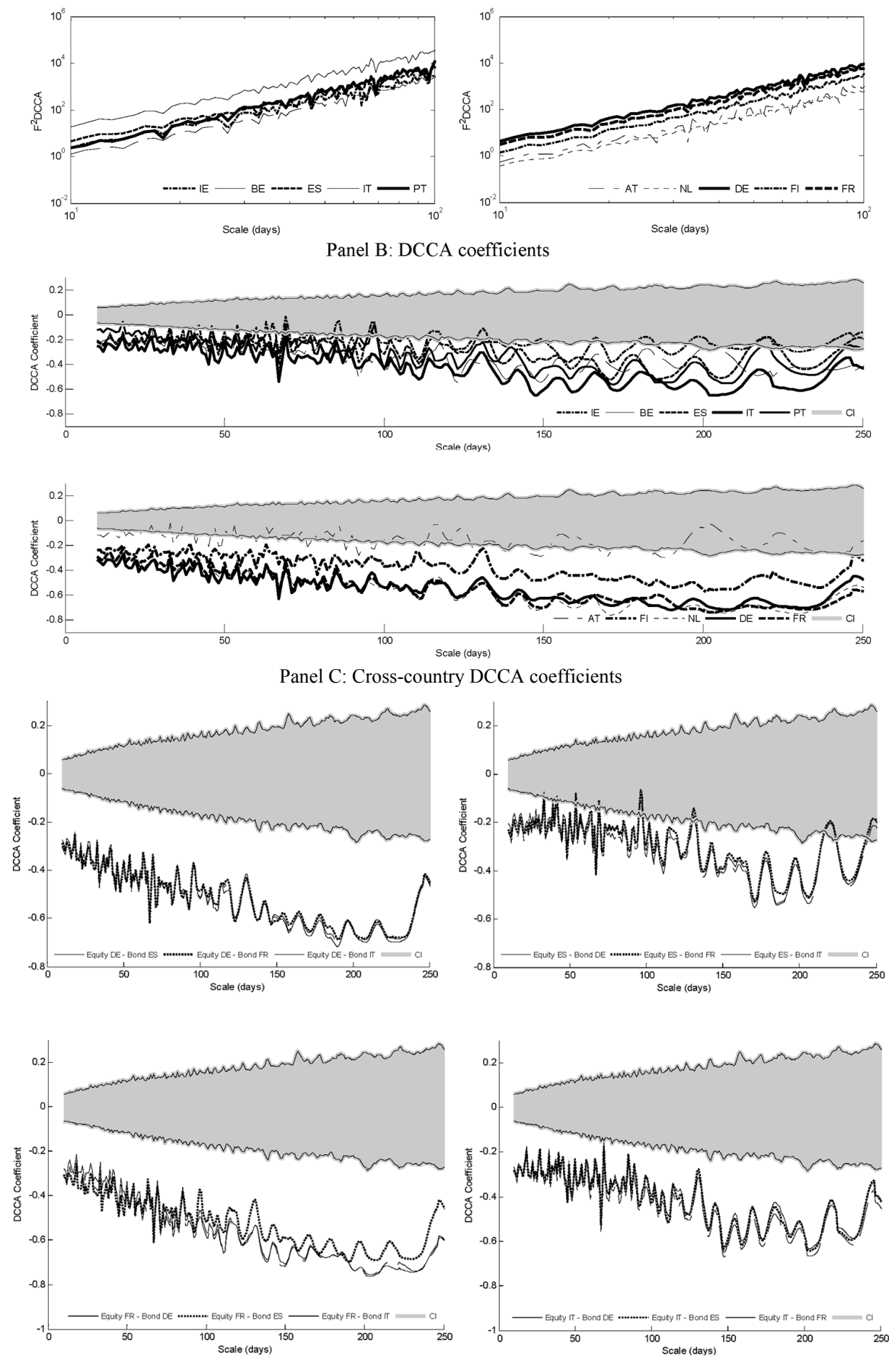
Figure 3 DCCA between equity and sovereign bonds from 2007.07 to 2012.06

Panel A: $2^{\text {nd }}$ order average fluctuation function (absolute value)
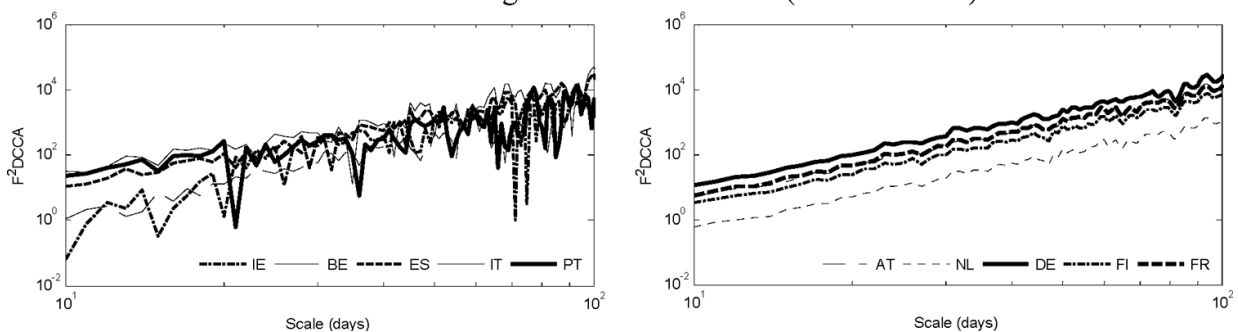

Panel B: DCCA coefficients
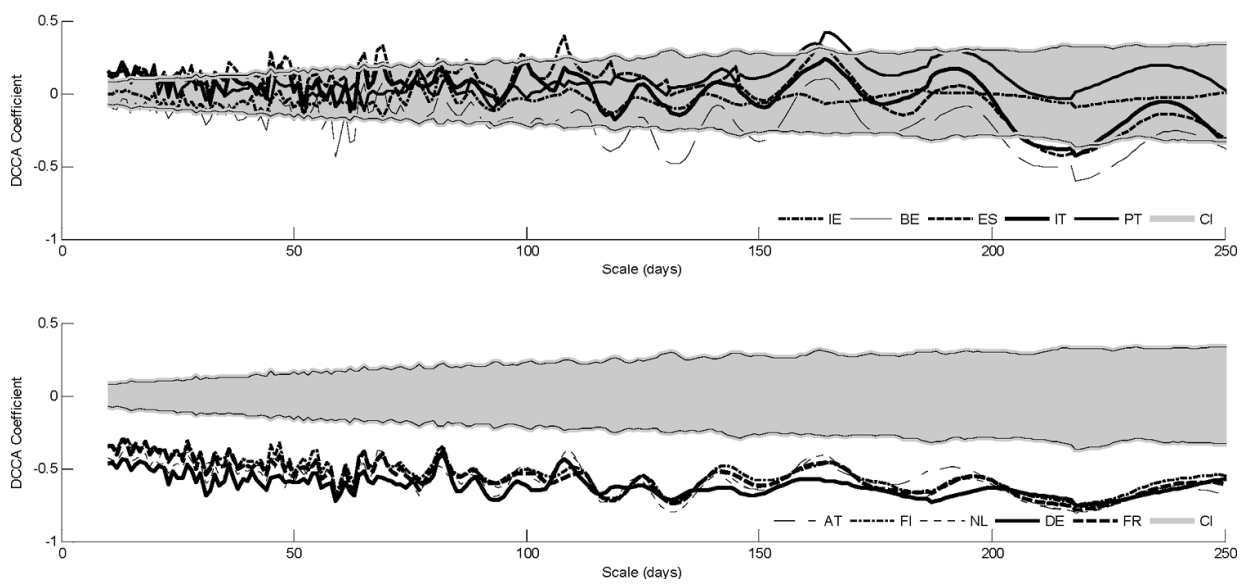

Panel C: Cross-country DCCA coefficients
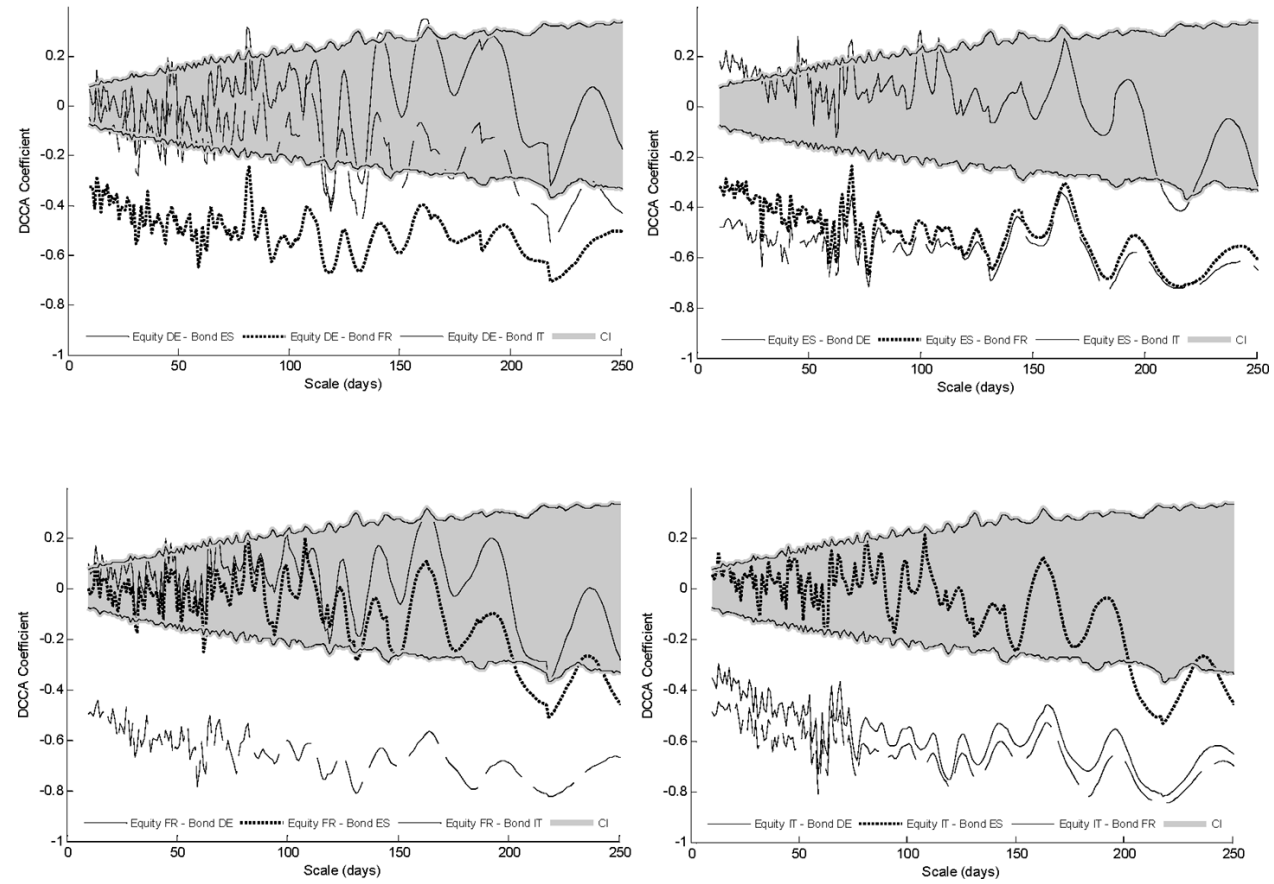
Figure 4 DCCA between equity and sovereign bonds from 2012.07 to 2018.09

Panel A: $2^{\text {nd }}$ order average fluctuation function (absolute value)
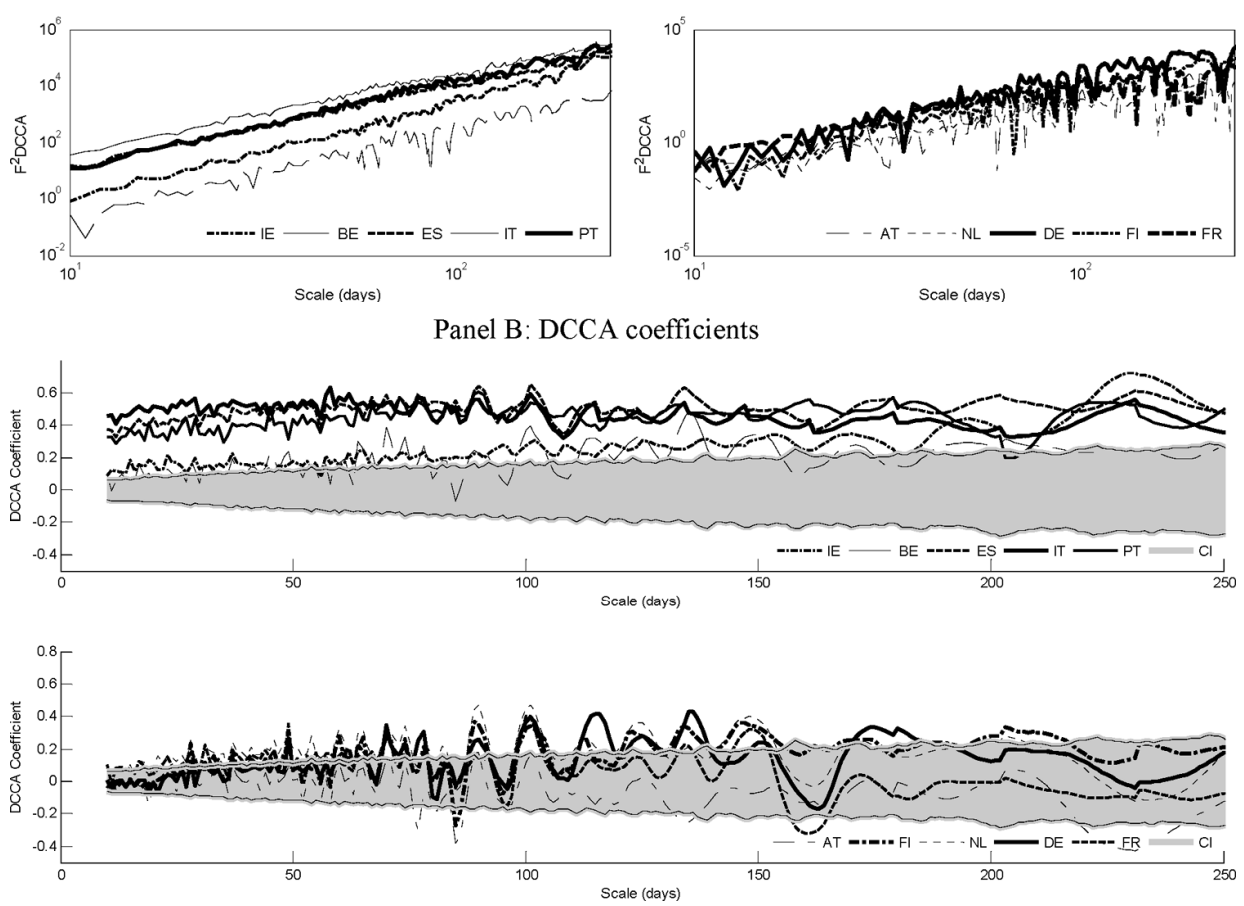

Panel C: Cross-country DCCA coefficients
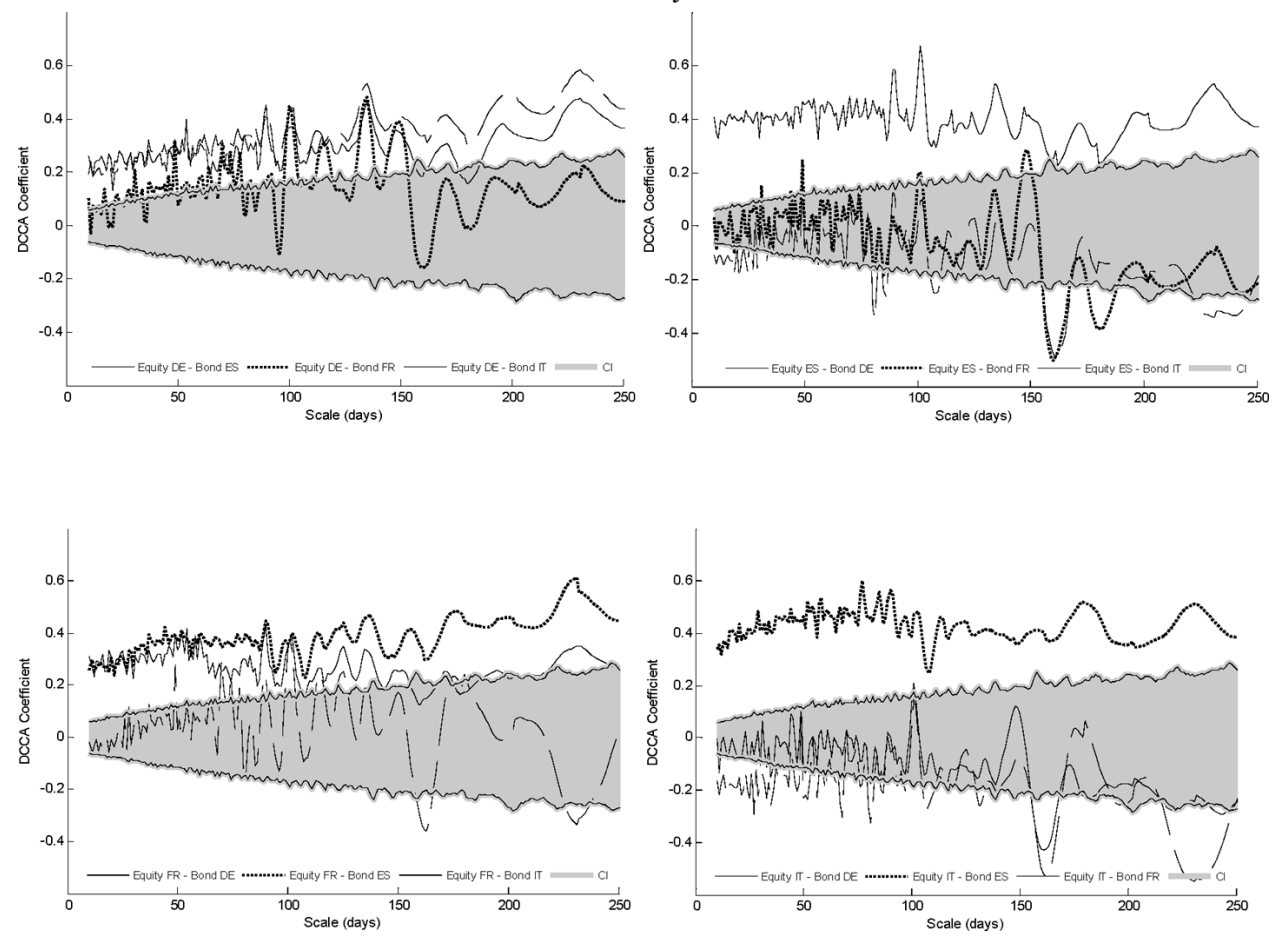
Table 1 Average of DCCA coefficients from 1999.01 to 2007.06 for different time scale intervals

\begin{tabular}{|c|c|c|c|c|c|c|c|c|c|c|}
\hline \multirow[b]{2}{*}{ Scale } & \multicolumn{10}{|c|}{ Countries } \\
\hline & $A T$ & $B E$ & $F I$ & $F R$ & $D E$ & $I E$ & $I T$ & $N L$ & $P T$ & $E S$ \\
\hline$n<50$ & -0.11 & -0.22 & -0.25 & -0.34 & -0.38 & -0.20 & -0.27 & -0.37 & -0.17 & -0.20 \\
\hline $50<=n<100$ & -0.13 & -0.31 & -0.31 & -0.47 & -0.48 & -0.19 & -0.33 & -0.48 & -0.24 & -0.21 \\
\hline $100<=n<150$ & -0.17 & -0.40 & -0.38 & -0.58 & -0.56 & -0.22 & -0.46 & -0.58 & -0.35 & -0.29 \\
\hline $150<=n<250$ & -0.19 & -0.40 & -0.48 & -0.67 & -0.65 & -0.26 & -0.54 & -0.68 & -0.43 & -0.37 \\
\hline
\end{tabular}

Significant values at the $5 \%$ level are signalled in bold.

Besides understanding the co-movement between debt-equity of each country, the correlations between stocks and bonds of different jurisdictions are also figured out. This additional assessment is useful to realise how concerns about the dynamics of financial instruments associated with a specific Member State may impinge on the performance of financial assets of other EMU jurisdictions. Due to parsimony reasons, this test is focused on the four biggest euro area economies (DE, FR, IT and ES). Panel C of Figure 2 then displays the estimated coefficients for the pre-crisis period. In line with the observations mentioned above, the negative correlations still hold in this context and intensify with the time scale. Therefore, there are no major differences across countries to be signalled.

These findings back up the perception that, in calmer times, equity and debt instruments tend to exhibit an inverse behaviour, broadly explained by the significantly positive stock returns and the downward trend in bond prices that induces the so called 'flight-from-quality' phenomenon. Likewise, in times of market turbulence, 'flight-toquality' episodes may happen as agents become more risk averse and opt to invest their funds in financial instruments that are deemed safer (see, e.g., Ilmanen, 2003; Chan et al., 2011). In short, as a negative correlation in the bond-equity relationship is one of the bedrocks of portfolio diversification, it tends to be explored by investors. Nevertheless, it is worth noting that while a negative correlation between these instruments may hold for the majority of the time, there are moments where it is not confirmed.

Moving on to the estimates for the turmoil period, two major comments come into play. Firstly, on account of the results displayed in Figure 3, the financial and the European sovereign debt crises brought changes in the behaviour of equity and bond markets and in their short-run and long-run relationships. Secondly, clues on fragmentation issues within the euro area may also be gleaned. In fact, as shown in Panel A, the linear dependence between $F_{D C C A}^{2}(n)$ and $n$ in a logarithmic scale is questionable for Member States with higher macroeconomic and financial fragilities. Corroborating these outcomes, Panel B shows that, while the negative linkage between stocks and bonds still holds for the higher-rated countries, this nexus broke for the most vulnerable ones as the long-run dynamic of the two instruments is not statistically significant at the $95 \% \mathrm{CI}$. Similarly to Table 1, Table 2 systematises the estimated DCCA coefficients in this period. From the comparison of these two tables, it is possible to confirm that, on average, correlations intensified in the case of AT, DE, FI, FR and NL. 
Table 2 Average of DCCA coefficients from 2007.07 to 2012.06 for different time scale intervals

\begin{tabular}{lcccccccccc}
\hline & \multicolumn{10}{c}{ Countries } \\
\cline { 2 - 11 } Scale & $A T$ & $B E$ & $F I$ & $F R$ & $D E$ & $I E$ & $I T$ & $N L$ & $P T$ & $E S$ \\
\hline$n<50$ & $\mathbf{- 0 . 4 1}$ & $\mathbf{- 0 . 1 2}$ & $\mathbf{- 0 . 4 0}$ & $\mathbf{- 0 . 4 2}$ & $\mathbf{- 0 . 5 4}$ & -0.05 & $\mathbf{0 . 1 4}$ & $\mathbf{- 0 . 4 8}$ & 0.06 & $\mathbf{0 . 1 4}$ \\
$50<=n<100$ & $\mathbf{- 0 . 5 4}$ & -0.15 & $\mathbf{- 0 . 5 0}$ & $\mathbf{- 0 . 5 3}$ & $\mathbf{- 0 . 6 0}$ & -0.04 & 0.05 & $\mathbf{- 0 . 5 5}$ & 0.02 & 0.12 \\
$100<=n<150$ & $\mathbf{- 0 . 6 1}$ & $-\mathbf{0 . 2 5}$ & $\mathbf{- 0 . 5 9}$ & $\mathbf{- 0 . 6 1}$ & $\mathbf{- 0 . 6 3}$ & -0.05 & 0.01 & $\mathbf{- 0 . 6 1}$ & 0.08 & 0.12 \\
$150<=n<250$ & $\mathbf{- 0 . 6 2}$ & -0.27 & $\mathbf{- 0 . 6 1}$ & $\mathbf{- 0 . 6 3}$ & $\mathbf{- 0 . 6 6}$ & -0.03 & -0.09 & $-\mathbf{0 . 6 4}$ & 0.16 & -0.12 \\
\hline
\end{tabular}

Significant values at the $5 \%$ level are signalled in bold.

Over the strain period, financial market participants penalised the Treasuries from countries with bonds perceived as presenting greater credit and liquidity risks. The higher risk premia led to higher government bond interest rates and to a downward trend in the price of the respective bonds. Similarly, equity indices had a negative performance stemming from the difficulties experienced by businesses operating in lower-rated countries, which were globally associated with a lower demand and higher borrowing costs. Based on this analysis, a positive relationship between the performance of these two instruments would be expected, which is confirmed in the short-run in the case of ES.

On the contrary, the stock-bond co-movements in higher-rated jurisdictions remained negative and statistically significant, supporting the fact that, driven by the worst outlook about future economic developments, investors fled stock and sovereign bond markets of vulnerable Member States looking to invest in financial assets of more solid economies (see, e.g., Dufour et al., 2017; Jammazi et al., 2015). These conclusions are supported by Panel C, since the correlation between stocks of euro area countries perceived as having lower credit quality and debt of less vulnerable economies remains negative in this subset. From this Panel the negative long-range cross-correlation between stocks and bonds of DE and FR that sustains the 'flight-to-quality' movements stands out. Indeed, there is evidence that in the presence of a stock market globally affected by the crises investors opted for Treasury securities issued by jurisdictions deemed safe. This observation suggests that, in their investment decisions, agents take into account both the financial instrument and the respective jurisdiction.

Regarding the results for the period from 2012.07 onwards shown in Figure 4, new patterns emerge. To begin with, according to Panel A, long-range cross-correlations between stocks and short-term sovereign bonds are identified for the euro area countries commonly perceived as presenting higher macroeconomic fragilities. Panel B and Table 3 provide further details on this relationship, which appears positive and statistically significant along the different scales for the aforementioned countries.

The correction of some economic and financial imbalances as well as the accommodative monetary policy conducted by the Eurosystem contributed to bring down sovereign bond interest rates, thereby increasing their price. In a similar fashion, these securities benefited from abating market worries about a possible EMU break-up. At the same time, also taking advantage of such economic and financial conditions, the performance of equity indices has been clearly positive since 2012, denoting an upward trend. As a consequence, equities and bonds exhibited a positive and statistically significant relationship in the third period under scrutiny at small and long time scales. 
This outcome is in line with prior literature that recognises the positive effect of easing monetary policy on boosting the performance of both stocks and bonds (see, e.g., Ilmanen, 2003; Dimic et al., 2016). According to Panel C, the combined effect mentioned above is particularly notorious for the most vulnerable countries as the coefficients associated with ES's stocks/IT's debt and IT's stocks/ES's debt are positive and statistically significant for all time scales.

As for the higher-rated countries, Panel A of Figure 4 reveals that $F_{D C C A}^{2}(n)$ oscillates (either increasing or decreasing) as a function of $n$. Based on Panel B and Table 3, cross-correlations are globally and statistically insignificant, hinting that investors' diversification benefits inched lower as the equity-bond relationship was no longer so predictable.

Table 3 Average of DCCA coefficients from 2012.07 to 2018.09 for different time scale intervals

\begin{tabular}{lcccccccccc}
\hline & \multicolumn{10}{c}{ Countries } \\
\cline { 2 - 11 } Scale & $A T$ & $B E$ & $F I$ & $F R$ & $D E$ & $I E$ & $I T$ & $N L$ & $P T$ & $E S$ \\
\hline$n<50$ & 0.00 & $\mathbf{0 . 1 2}$ & 0.06 & $\mathbf{0 . 1 2}$ & 0.04 & $\mathbf{0 . 1 5}$ & $\mathbf{0 . 5 0}$ & $\mathbf{0 . 1 5}$ & $\mathbf{0 . 3 7}$ & $\mathbf{0 . 4 4}$ \\
$50<=n<100$ & -0.05 & $\mathbf{0 . 1 6}$ & 0.11 & 0.11 & 0.11 & $\mathbf{0 . 2 0}$ & $\mathbf{0 . 5 1}$ & $\mathbf{0 . 1 9}$ & $\mathbf{0 . 4 8}$ & $\mathbf{0 . 5 2}$ \\
$100<=n<150$ & -0.08 & $\mathbf{0 . 2 7}$ & $\mathbf{0 . 2 3}$ & 0.13 & $\mathbf{0 . 2 3}$ & $\mathbf{0 . 2 7}$ & $\mathbf{0 . 4 5}$ & $\mathbf{0 . 2 5}$ & $\mathbf{0 . 4 7}$ & $\mathbf{0 . 5 0}$ \\
$150<=n<250$ & -0.12 & $\mathbf{0 . 2 4}$ & 0.23 & -0.06 & 0.14 & $\mathbf{0 . 4 0}$ & $\mathbf{0 . 4 2}$ & 0.14 & $\mathbf{0 . 4 6}$ & $\mathbf{0 . 5 1}$ \\
\hline
\end{tabular}

Significant values at the $5 \%$ level are signalled in bold.

\subsection{ADCCA: asymmetric long-range cross-correlation}

In view of circumventing the insufficiency of the DCCA to detect and quantify an eventual asymmetric relationship between the two instruments under inspection, the ADCCA is employed, which builds on the upward and downward trends of both stock and sovereign bond prices.

The results from this assessment are summarised in Table 4 with an equity/bond increase and an equity/bond decrease denoting an uptrend and a downtrend, respectively. Panels $\mathrm{A}$ to $\mathrm{C}$ hence provide information on how the asymmetric feature evolves, on average, over various time scale intervals for the three sub-periods under inspection. Further details on this analysis are presented in Appendix 1.

According to Panel A, despite being almost always negative in both trend directions, as expected, cross-correlations tend to be stronger when stock prices edge downwards and sovereign bond prices edge upwards. This finding confirms that investors tend to overweigh 'bad' news relative to 'good' news in financial markets, i.e., the 'flight-to-quality' episodes observed when the economic outlook deteriorates seem to be more relevant than the so-called 'flight-to-yield' tendency associated with a higher risk appetite.

From Panel B some conclusions can be sketched in relation to the crises period. Firstly, when compared with the pre-crises period, and focusing on higher-rated countries, cross-correlation coefficients remain globally negative and stronger when stock prices decrease and government bond prices increase. This outcome tallies with the abovementioned 'flight-to-quality' movement in turmoil periods. Secondly, asymmetry in terms of upward and downward trends is also more prominent in this period with 
cross-correlations when the stock market is going up and the bond market is coming down, varying across the different time scale intervals and being even statistically insignificant.

The empirical results for the period after mid-2012 are exhibited in Panel C. In this subset the cases of ES, IE, IT and PT bear out with cross-correlations that tend to be positive, stronger and more stable when both stock and debt markets rise. This asymmetry in comparison with downward trends of stock and bond prices may be associated with the policy actions undertaken to stabilise financial markets and to strengthen economic activity, which contributed to bring down sovereign interest rates in more vulnerable jurisdictions along with a good performance in equity indices.

In relation to these findings, it is worth noting that the ADCCA brings relevant details on the dynamics of these two assets. In a nutshell, there is evidence that investors take the worst-case approach to novel information, reacting more towards 'bad' news than 'good' news in financial markets (see, e.g., Veronesi, 1999; Epstein and Schneider, 2008). In addition, it is clear the importance of the policy measures taken to support economic growth, mitigate creditworthiness concerns, alleviate fragmentation issues and promote financial stability.

\subsection{Causality}

As previously mentioned, the Toda and Yamamoto (1995) Granger non-causality approach requires that the order of integration of the series, $d_{\max }$, and the optimal lag, $k$, should be pre-determined. The maximum order of integration was inferred from the ADF and PP unit root tests. In addition, the optimal VAR lag length was chosen by minimising information criteria.

The pre-crises period results for the causality between the debt of the euro area countries and the respective equities are shown in Panel A of Table 5. The significance of the $p$-values for the Modified-Wald chi-square statistics reveals that bidirectional Granger causality predominates. In the few cases (BE and PT) for which one-way causality is observed, it runs from debt to equity markets.

Table 5-Panel B shows the results of the Toda and Yamamoto (1995) test in the crises period. Bidirectional causality is globally detected for higher-rated countries, while unidirectional relationship is mainly found in some vulnerable jurisdictions (ES and IT). In the cases where a one-way causality is observed, statistical evidence, at the $5 \%$ significance level, is found, showing that the stock market does Granger-cause the behaviour of sovereign bonds. These findings seem to be consistent with the conclusions found in previous sections, supporting cross-country differences and reflecting the extent to which they were affected by the crises.

Granger causality assessment from mid-2012 onwards is displayed in Table 5-Panel C. Overall, there are no spillover effects either from stocks to sovereign bonds or from debt to equity markets, as the null hypothesis for the majority of euro area countries is not rejected at the $10 \%$ significance level. The few exceptions in which a causal relationship is noted are in ES, IT and PT. However, in these countries it is not possible to identify a clear pattern in terms of the direction of the causality. These outcomes globally reflect how measures taken with the crises to maintain the stability of markets affected the normal linkage between these two financial classes. 
Table 4 Average of ADCCA coefficients over the three sub-periods for different time scale intervals

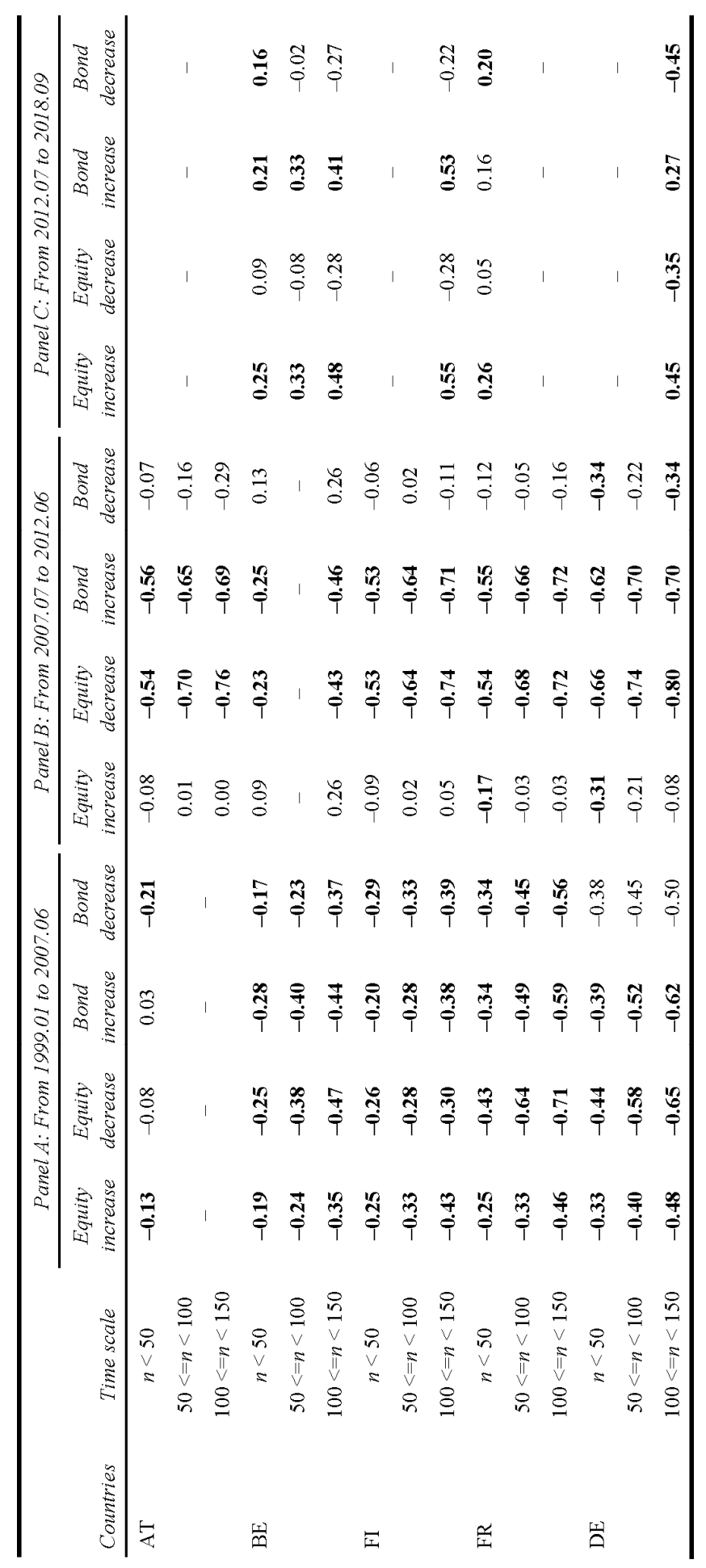


Table 4 Average of ADCCA coefficients over the three sub-periods for different time scale intervals (continued)

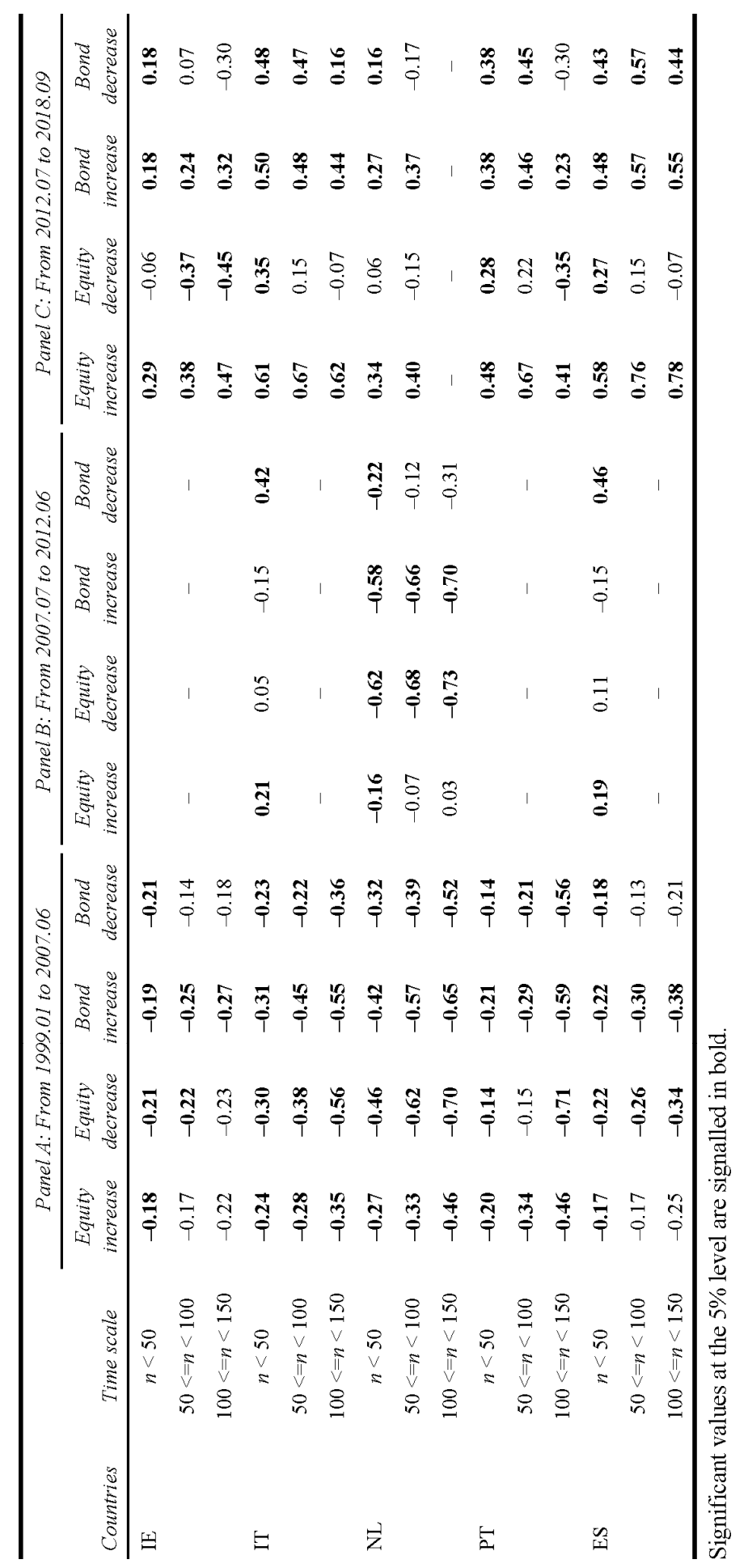


Table 5 Causality between equity and sovereign bonds over the three sub-periods

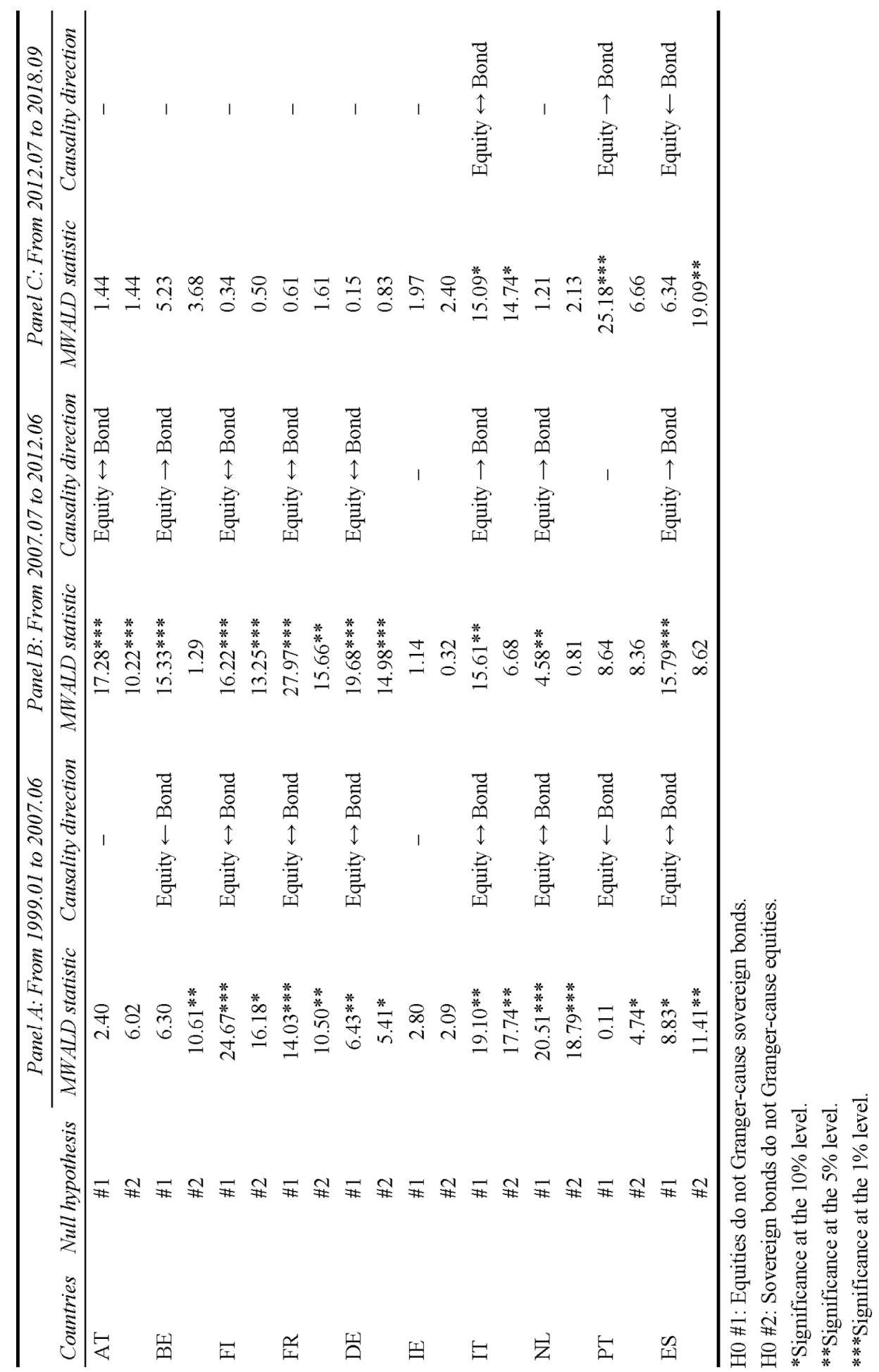




\section{Conclusions}

The link between stocks and bonds is one of the most scrutinised relationships in the financial landscape owing to its relevance to asset allocation, risk management and monetary policy mechanism. Historically, there were periods where correlations were negative and others where they were positive, ranging between strong and weak values.

The analysis of these dynamics is especially crucial within the EMU as the integration of the capital markets can help to cushion global shocks, thereby enhancing the resilience of the euro area as a whole. In this context, this paper offers an original attempt to go into further detail about how the interconnectedness of stocks and bonds have evolved within country and across countries in the euro area since the introduction of the single currency. Once investors have their own investment time horizon, there is also special interest in the multiscale properties of the relationship.

To accomplish this goal, the study focuses on the first 10 countries which have joined the euro area, excluding Luxemburg due to data constrains. The sample underpinning the empirical analysis spans from 1999.01 to 2018.09 and the methodology used builds on the DDCA and on its asymmetric version, which attempts to assess powerlaw cross-correlations between two time series regardless of the potential non-stationary. Finally, going from correlation to causality, the Toda and Yamamoto (1995) test is employed. Overall, the main conclusions of this paper can be summarised as follows.

Firstly, results by country reveal significant variability of co-movements from jurisdiction to jurisdiction. Additionally, the sign and the intensity of the crosscorrelations differ considerably depending on the specific period under analysis and on the time scale. Until 2007, a global bidirectional and negative cross-correlation between stocks and bonds, which becomes stronger as the time scale increases, is detected for EMU Member States. However, the financial and the sovereign debt crises introduced new figures since the negative association between stocks and bonds intensified for the higher-rated countries, but broke for the most vulnerable ones, hinting to fragmentation issues in the euro area capital markets. Moreover, the causal relationships were affected differently during that period. Even from mid-2012 onwards, these co-movements did not return to the initial levels as the correlations between stocks and bonds of countries considered riskier ended up being positive without a clear pattern in terms of causality.

Secondly, from the cross-country investigation, there is evidence that during turmoil periods investors tend to move away from stock and sovereign bond markets of vulnerable Member States to invest in high-quality liquid assets, which reinforces the signals of heterogeneity in the euro area. Furthermore, a preference for Treasury securities issued by jurisdictions deemed safer stands out as it is clear that, in the management of their portfolio, investors take into account both the type of financial instrument and the respective jurisdiction.

Thirdly, by isolating upward trends from downward ones, it is interesting to realise that stock-bond correlations are not indifferent to market upturns and downturns. Indeed, the empirical findings indicate that 'flight-to-quality' movements when the economic outlook deteriorates seem to be more relevant than 'flight-to-yield' episodes verified in contexts of appetite for higher risk. Moreover, the positive and stronger cross-correlations identified from mid-2012 onwards when both stock and debt markets increase emphasise the role of measures undertaken by policymakers in promoting the stability of financial markets. 
All in all, this paper provides a deep analysis of the dynamics of euro area stocks and sovereign bonds. In particular, it became obvious that cross-correlations depend on the time scale and on the economic and financial environment. Furthermore, this research highlights the heterogeneity of the EMU, thus strengthening the relevance of monitoring the euro area financial integration.

All the conclusions herein are of special interest to analysts and investors as well as to policymakers. Accordingly, the former may improve their diversification strategies and risk mitigation techniques given that agents usually invest in several markets and consider various time horizons. Indeed, the empirical cross-correlation matrices obtained by the ADCCA approach exhibit some interesting properties at different time scales, which are not caught by the traditional methodologies that resort to just a few lags to assess this linkage. Also, this study may deserve the interest of policymakers since it draws attention to the integration in a currency union and the relevance of policy measures adopted to alleviate financial market tensions and to reduce fragmentation issues.

In terms of avenues for future research, the paper points out the need to further monitor the behaviour of correlations between stocks and bonds, given that the existing literature on this subject is still incipient, tending to assess the dynamics of each market per se. Last but not least, it would be meritorious to conduct similar analyses for other economies (advanced but also emerging markets) and to explore the fundamentals behind the observed co-movements so that future cross-asset dynamics can be anticipated as much as possible.

\section{Acknowledgements}

The authors are grateful for the valuable comments received from the editor and the anonymous reviewers. They would also like to express their gratitude to Professor Zebende for his prompt and enlightening collaboration.

Pedro was supported by Fundação para a Ciência e a Tecnologia, grant UID/GES/00315/2019.

João Nicolau was partially supported by the Project CEMAPRE - UID/MULTI/ 00491/2019 and PTDC/EGE-ECO/28924/2017 financed by FCT/MCTES through national funds.

\section{Disclaimer}

The views expressed are those of the authors and do not necessarily represent those of the Banco de Portugal or the Eurosystem.

\section{References}

Andersson, M., Krylova, E. and Vähämaa, S. (2008) 'Why does the correlation between stock and bond returns vary over time?', Applied Financial Economics, Vol. 18, No. 2, pp.139-151.

Bashir, U., Yu, Y., Hussain, M. and Zebende, G. (2016) 'Do foreign exchange and equity markets co-move in Latin American region? Detrended cross-correlation approach', Physica A: Statistical Mechanics and its Applications, Vol. 462, pp.889-897. 
Baur, D.G. and Lucey, B.M. (2008) 'Flights and contagion - an empirical analysis of stock-bond correlations', Journal of Financial Stability, Vol. 5, No. 4, pp.339-352.

Cappiello, L., Engle, R.F. and Sheppard, K. (2006) 'Asymmetric dynamics in the correlations of global equity and bond returns', Journal of Financial Econometrics, Vol. 4, No. 4, pp.537-572.

Chan, K.F., Treepongkaruna, S., Brooks, R. and Gray, S. (2011) 'Asset market linkages: evidence from financial, commodity and real estate assets', Journal of Banking \& Finance, Vol. 35, No. 6, pp.1415-1426.

Cipollini, A., Coakley, J. and Lee, H. (2015) 'The European sovereign debt market: from integration to segmentation', The European Journal of Finance, Vol. 21, No. 2, pp.111-128.

Connolly, R., Stivers, C. and Sun, L. (2005) 'Stock market uncertainty and the stock-bond return relation', Journal of Financial and Quantitative Analysis, Vol. 40, No. 1, pp.161-194.

de Goeij, P. and Marquering, W. (2004) 'Modelling the conditional covariance between stock and bonds returns: a multivariate GARCH approach', Journal of Financial Econometrics, Vol. 2, No. 4, pp.531-564.

Dean, W.G., Faff, R.W. and Loudon, G.F. (2010) 'Asymmetry in return and volatility spillover between equity and bond markets in Australia', Pacific-Basin Finance Journal, Vol. 18, No. 3, pp.272-289.

Dickey, D.A. and Fuller, W.A. (1981) 'Likelihood ratio statistic for autoregressive times series with a unit root', Econometrica, Vol. 49, No. 4, pp.1057-1072.

Dimic, N., Kiviaho, J., Piljak, V. and Äijö, J. (2016) 'Impact of financial market uncertainty and macroeconomic factors on stock-bond correlation in emerging markets', Research in International Business and Finance, Vol. 36, No. C, pp.41-51.

Draghi, M. (2012) Speech at the Global Investment Conference, London, 26 July.

Dufour, A., Stancu, A. and Varotto, S. (2017) 'The equity-like behaviour of sovereign bonds', Journal of International Financial Markets, Institutions and Money, Vol. 48, No. C, pp.25-46.

Ehrmann, M. and Fratzscher, M. (2017) 'Euro area government bonds-fragmentation and contagion during the sovereign debt crisis', Journal of International Money and Finance, Vol. 70, No. C, pp.26-44.

Epstein, L.G. and Schneider, M. (2008) 'Ambiguity, information quality and asset pricing', Journal of Finance, Vol. 63, No. 1, pp.197-228.

Fonseca, J.S. (2016) 'Euro area stock markets performance comparison and its dependence on macroeconomic variables', International Journal of Monetary Economics and Finance, Vol. 9, No. 3, pp.245-266.

Gödl, M. and Kleinert, J. (2016) 'Interest rate spreads in the eurozone: Fundamentals or sentiments?', Review of World Economics, Vol. 152, No. 3, pp.449-475.

Gulko, L. (2002) 'Decoupling', The Journal of Portfolio Management, Vol. 28, No. 3, pp.59-66.

Hartmann, P., Straetmans, S. and Devries, C. (2004) 'Asset market linkages in crisis periods', Review of Economics and Statistics, Vol. 86, No. 1, pp.313-326.

Iheanacho, E. (2017), Impact of oil price shocks on stock market returns: Toda Yamamoto causality', Journal of Finance, Banking and Investment, Vol. 4, No. 1, pp.100-111.

Ilmanen, A. (2003) 'Stock-bond correlations', Journal of Fixed Income, Vol. 13, No. 2, pp.55-66.

Jain, A. and Ghosh, S. (2013) 'Dynamics of global oil prices, exchange rate and precious metal prices in India', Resources Policy, Vol. 38, No. 1, pp.88-93.

Jammazi, R., Tiwari, A.K., Ferrer, R. and Moya, P. (2015) 'Time-varying dependence between stock and government bond returns: international evidence with dynamic copulas', North American Journal of Economics and Finance, Vol. 33, pp.74-93.

Kim, S. and In, F. (2007) 'On the relationship between changes in stock prices and bond yields in the G7 countries: wavelet analysis', Journal of International Financial Markets, Institutions and Money, Vol. 17, No. 2, pp.167-179. 
Kristoufek, L. (2014) 'Measuring correlations between non-stationary series with DCCA coefficient', Physica A: Statistical Mechanics and its Applications, Vol. 402, No. C, pp.291-298.

Lukić, V. (2016) 'Integration of government bond market in the euro area and monetary policy', Journal of Central Banking Theory and Practice, Vol. 5, No. 1, pp.71-97.

Nguyen, C. and Nguyen, T. (2014) 'Analyzing dependence structure of equity, bond and money markets by using time-varying copulas', International Journal of Economics and Finance, Vol. 6, No. 3, pp.37-54.

Peng, C-K., Buldyrev, S.V., Havlin, S., Simons, M., Stanley, H.E. and Goldberger, A.L. (1994) 'Mosaic organization of DNA nucleotides', Physical Review E, Vol. 49, No. 2, pp.1685-1689.

Perego, E.R. and Vermeulen, W.N. (2016) 'Macro-economic determinants of European stock and government bond correlations: a tale of two regions', Journal of Empirical Finance, Vol. 37, No. C, pp.214-232.

Phillips, P.C.B. and Perron, P. (1988) 'Testing for a unit root in time series regression', Biometrika, Vol. 75, No. 2, pp.335-346.

Podobnik, B. and Stanley, H.E. (2008) 'Detrended cross-correlation analysis: a new method for analyzing two nonstationary time series', Physical Review Letters, Vol. 100, No. 8, pp.38-71.

Podobnik, B., Jiang, Z-Q., Zhou, W-X. and Stanley, H.E. (2011) 'Statistical tests for power-law cross-correlated processes, Physical Review E, Vol. 84, No. 6, p.066118.

Ribeiro, P.P., Cermeño, R. and Curto, J.D. (2017) 'Sovereign bond markets and financial volatility dynamics: panel-GARCH evidence for six euro area countries', Finance Research Letters, Vol. 21, pp.107-114.

Skintzi, V.D. (2019) 'Determinants of stock-bond market comovement in the Eurozone under model uncertainty', International Review of Financial Analysis, Vol. 61, No. C, pp.20-28.

Toda, H.Y. and Yamamoto, T. (1995) 'Statistical inference in vector autoregressions with possibly integrated processes', Journal of Econometrics, Vol. 66, No. 1, pp.225-250.

Veronesi, P. (1999) 'Stock market overreaction to bad news in good times: a rational expectations equilibrium model', Review of Financial Studies, Vol. 12, pp.975-1007.

Wang, F. (2016) 'A novel coefficient for detecting and quantifying asymmetry of California electricity market based on asymmetric detrended cross-correlation analysis', Chaos: An Interdisciplinary Journal of Nonlinear Science, Vol. 26, No. 6, p.063109.

Wang, Y., Wei, Y. and Wu, C. (2011) 'Detrended fluctuation analysis on spot and futures markets of West Texas Intermediate crude oil', Physica A: Statistical Mechanics and its Applications, Vol. 390, No. 5, pp.864-875.

Wolde-Rufael, Y. (2006) 'Electricity consumption and economic growth: a time series experience for 17 African countries', Energy Policy, Vol. 34, No. 10, pp.1106-1114.

Wu, C-C. and Lin, Z-Y. (2014) 'An economic evaluation of stock-bond return comovements with copula-based GARCH models', Quantitative Finance, Vol. 14, No. 7, pp.1283-1296.

Yang, J., Zhou, Y. and Wang, Z. (2009) 'The stock-bond correlation and macroeconomic conditions: one and a half centuries of evidence, Journal of Banking and Finance, Vol. 32, No. 4, pp.670-680.

Zebende, G.F. (2011) 'DCCA cross-correlation coefficient: quantifying level of cross-correlation', Physica A: Statistical Mechanics and its Applications, Vol. 390, No. 4, pp.614-618.

Zebende, G.F., Silva, M.F. and Filho, A.M. (2013) 'DCCA cross-correlation coefficient differentiation: theoretical and practical approaches', Physica A: Statistical Mechanics and its Applications, Vol. 392, No. 8, pp.1756-1761. 


\section{Notes}

${ }^{1}$ As documented by Ilmanen (2003), this fact is explained by the dominance of discount rates changes over cash flow expectations changes.

${ }^{2}$ Luxembourg is not included due to data availability constraints. In addition, the remaining countries that adopted the euro as currency at a later stage are not included in this database to avoid dealing with different number of observations per jurisdiction.

${ }^{3}$ These cut-offs were found to catch the onset of the early warnings signing the breakdown of trust within the financial system as well as considering Draghi's (2012) speech at the Global Investment Conference on 26 July, 2012.

${ }^{4}$ The optimal lag length was determined by the SBC.

${ }^{5}$ These results are available from the authors upon request.

${ }^{6}$ The code was developed by the authors in Matlab.

\section{Appendix 1}

Figure A1 ADCCA between equity and sovereign bonds from 1999.01 to 2007.06

Panel A: ADCCA coefficients for DE
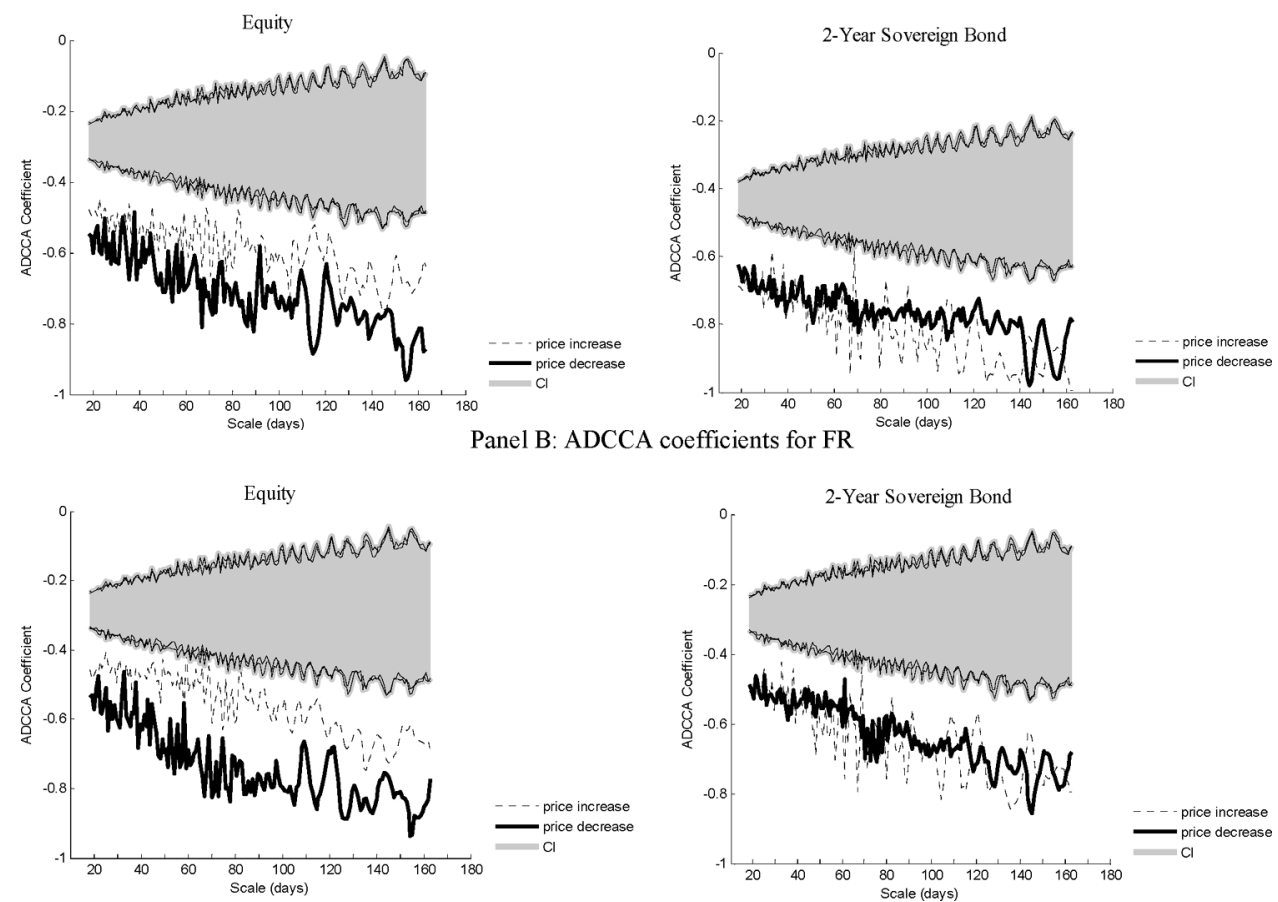
Figure A1 ADCCA between equity and sovereign bonds from 1999.01 to 2007.06 (continued)

Panel C: ADCCA coefficients for ES
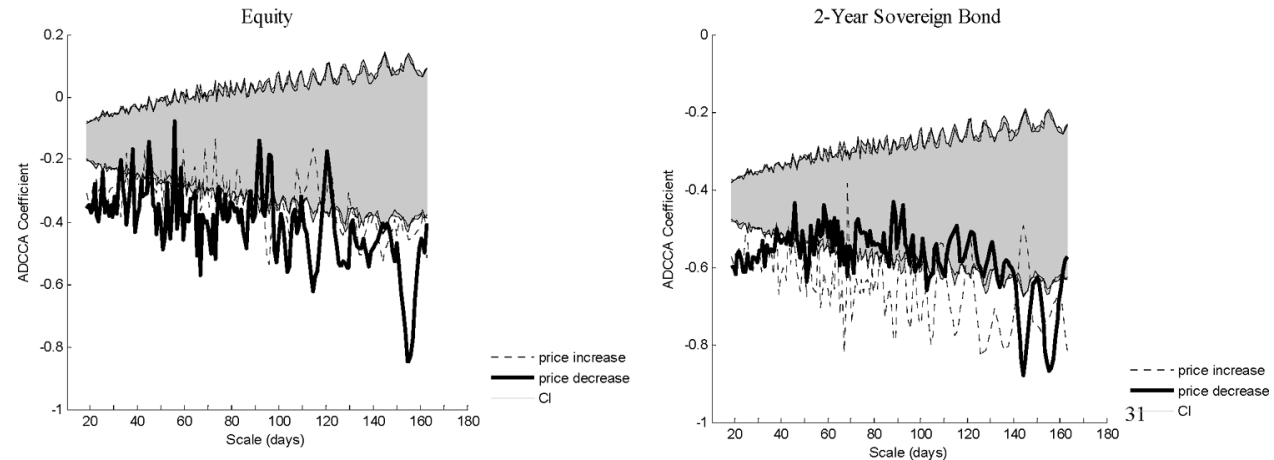

Panel D: ADCCA coefficients for IT
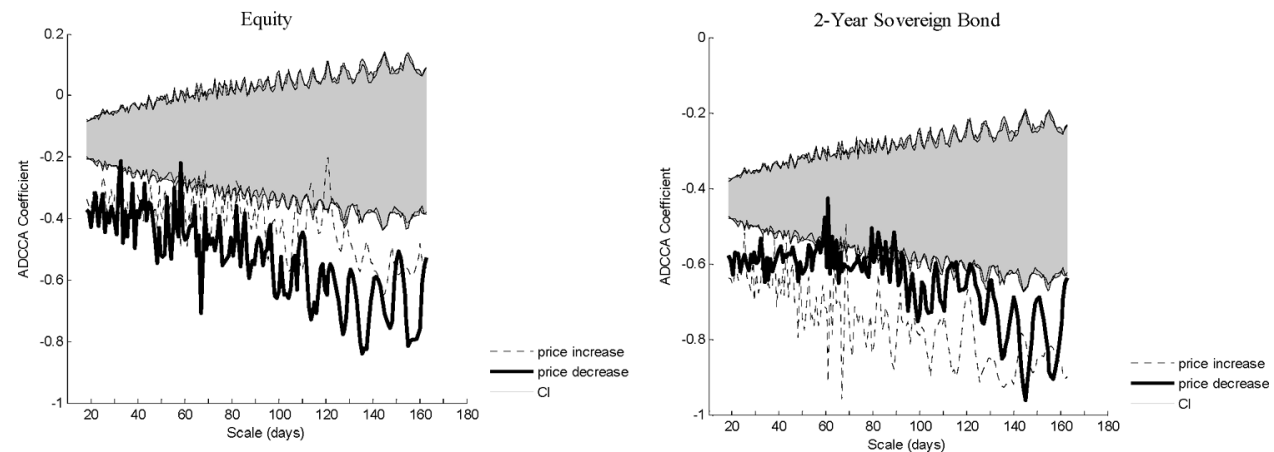

Figure A2 ADCCA between equity and sovereign bonds from 2007.07 to 2012.06

Panel A: ADCCA coefficients for DE
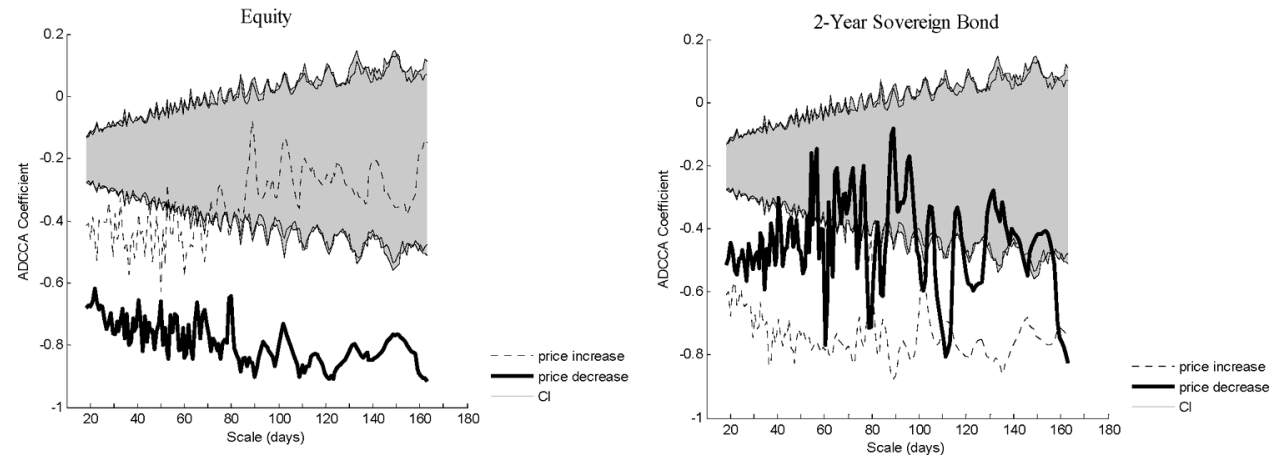
Figure A2 ADCCA between equity and sovereign bonds from 2007.07 to 2012.06 (continued) Panel B: ADCCA coefficients for FR
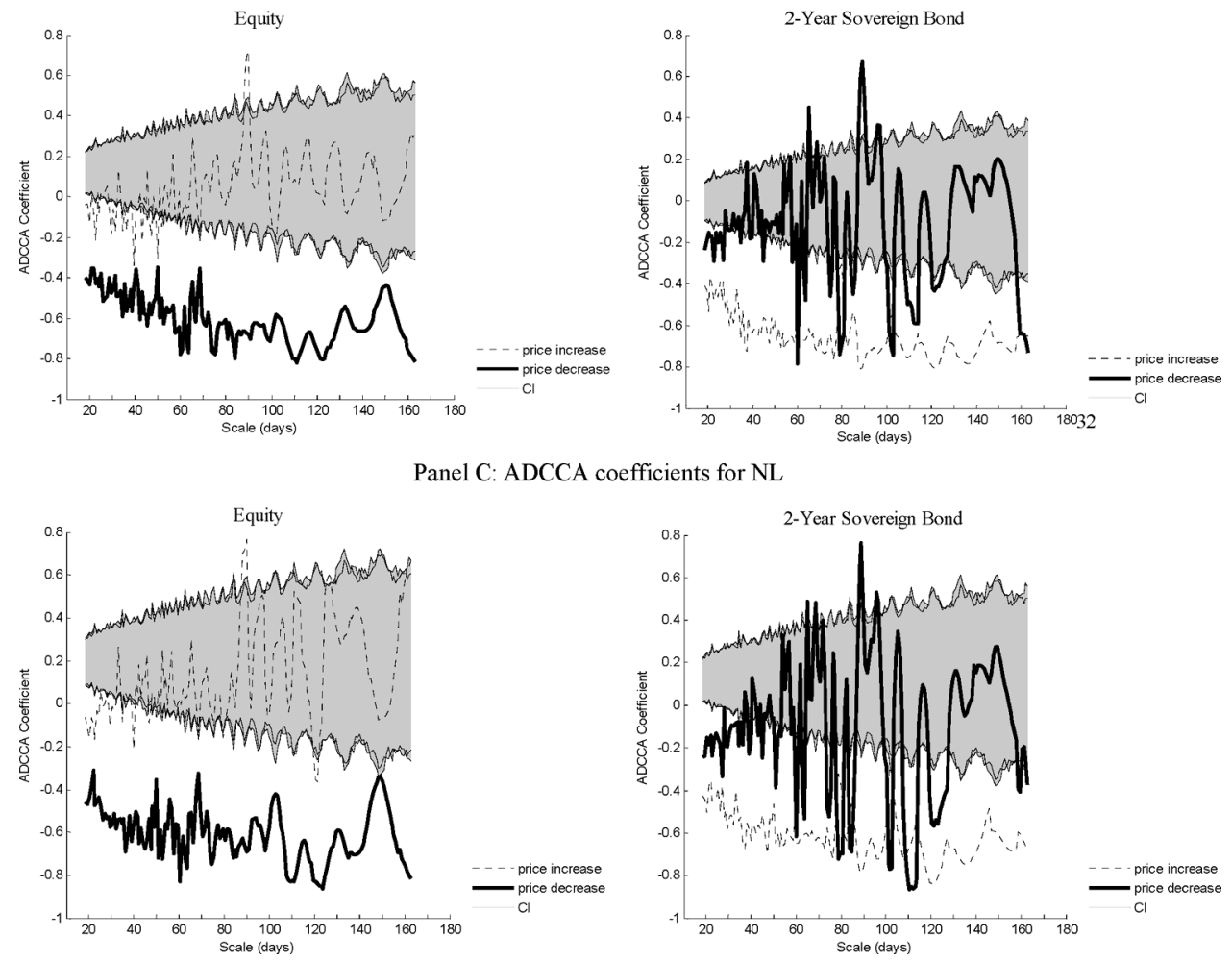

Panel D: ADCCA coefficients for AT
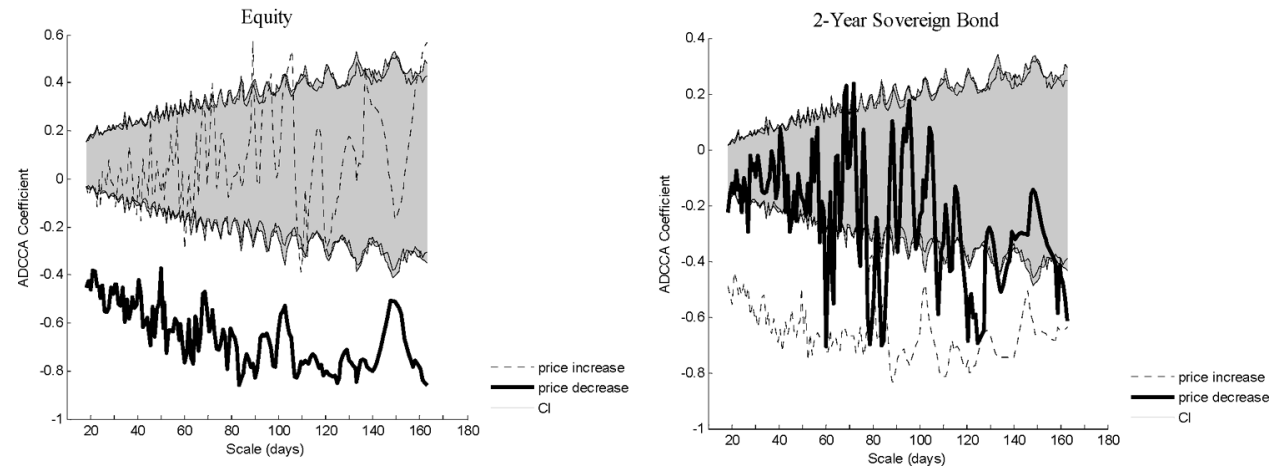
Figure A3 ADCCA between equity and sovereign bonds from 2012.07 to 2018.09

Panel A: ADCCA coefficients for ES
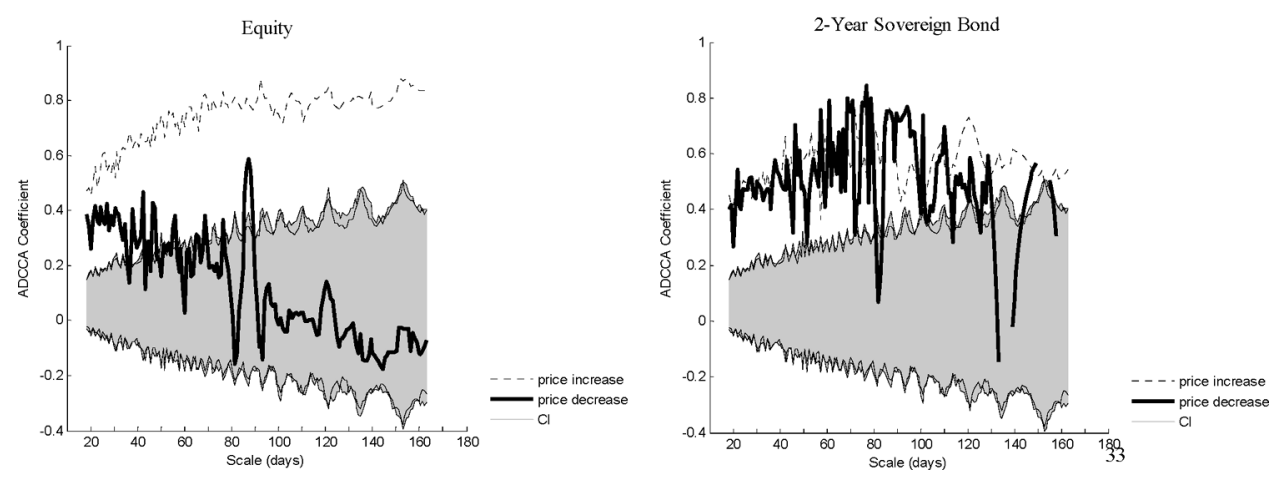

Panel B: ADCCA coefficients for IT
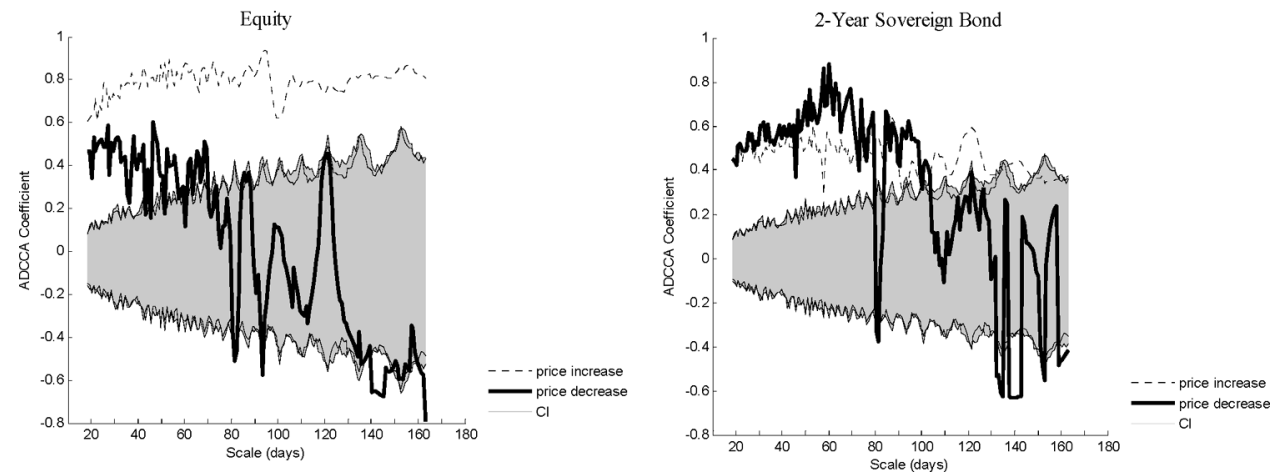

Panel C: ADCCA coefficients for PT
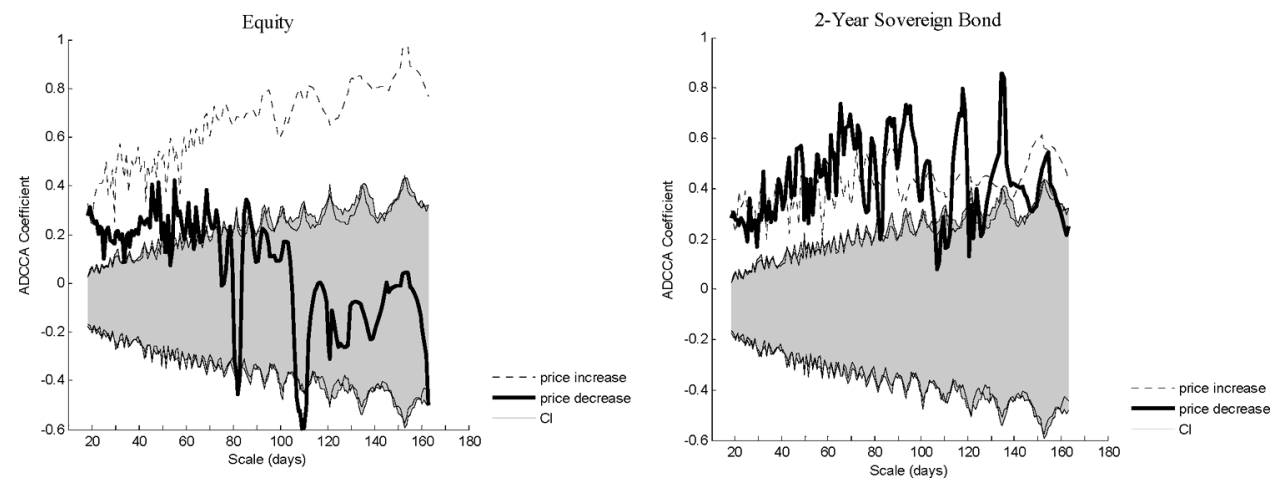